\title{
Characterisation of dissolved organic compounds in hydrothermal fluids by stir bar sorptive extraction - gas chomatography - mass spectrometry. Case study: the Rainbow field $\left(36^{\circ} \mathrm{N}\right.$, Mid-Atlantic Ridge)
}

\author{
Cecile Konn ${ }^{1,2^{*}}$, Jean-Luc Charlou' ${ }^{1}$, Jean-Pierre Donval ${ }^{1}$ and Nils G Holm²
}

\begin{abstract}
The analysis of the dissolved organic fraction of hydrothermal fluids has been considered a real challenge due to sampling difficulties, complexity of the matrix, numerous interferences and the assumed ppb concentration levels. The present study shows, in a qualitative approach, that Stir Bar Sorptive Extraction (SBSE) followed by Thermal Desorption - Gas Chromatography - Mass Spectrometry (TD-GC-MS) is suitable for extraction of small sample volumes and detection of a wide range of volatile and semivolatile organic compounds dissolved in hydrothermal fluids. In a case study, the technique was successfully applied to fluids from the Rainbow ultramafic-hosted hydrothermal field located at $36^{\circ} 14^{\prime} \mathrm{N}$ on the Mid-Atlantic Ridge (MAR). We show that n-alkanes, mono- and polyaromatic hydrocarbons as well as fatty acids can be easily identified and their retention times determined. Our results demonstrate the excellent repeatability of the method as well as the possibility of storing stir bars for at least three years without significant changes in the composition of the recovered organic matter. A preliminary comparative investigation of the organic composition of the Rainbow fluids showed the great potential of the method to be used for assessing intrafield variations and carrying out time series studies. All together our results demonstrate that SBSE-TD-GC-MS analyses of hydrothermal fluids will make important contributions to the understanding of geochemical processes, geomicrobiological interactions and formation of mineral deposits.
\end{abstract}

Keywords: Sample preparation, Extraction, Organic compounds, Hydrothermal fluids, Ultramafic rocks

\section{Background}

Organic geochemistry is of major importance in both geosciences and life sciences [1]. Investigation, identification and quantification of organic compounds (e.g., biomarkers, prebiotic molecules, hydrocarbons) help in understanding the evolution of the Earth and constraining biogeochemical processes that occurred or are still occurring on Earth. The organic geochemistry of rivers, lakes, estuaries, sedimentary basins, terrestrial rocks and oil reservoirs is being extensively studied. Despite the likely significant impact of

\footnotetext{
* Correspondence: cecile.konn@ifremer.fr

'Laboratoire Géochimie Métallogénie, UR Géosciences Marines, Ifremer, Ctr Brest, B.P.70 29280 Plouzané, France ${ }^{2}$ Department of Geological Sciences, Geochemistry section, Stockholm
University, 10691 Stockholm, Sweden Department of Geological Sciences,
University, 10691 Stockholm, Sweden
}

\section{Biomed Central}

(c) 2012 Konn et al.; licensee BioMed Central Ltd. This is an Open Access article distributed under the terms of the Creative Commons Attribution License (http://creativecommons.org/licenses/by/2.0), which permits unrestricted use, distribution, and reproduction in any medium, provided the original work is properly cited.

hydrothermal circulation on the ocean global energy and matter fluxes and the implication of hydrothermal systems in major issues such as the origin of life [2,3], publications on the organic geochemistry of hydrothermal systems are rare. The literature comprises a few studies devoted to the organic contents of hydrothermal sulphide deposits [4], serpentinites [5], carbonate chimneys [6,7] and sediments [8]. In terms of fluids, the abiotic synthesis of dissolved hydrocarbon gases [9-11] as well as the presence of larger dissolved hydrocarbons and other organic molecules [12-14] in fluids from ultramafic-hosted systems at slow spreading ridges has been reported.

Hydrothermal vents are found both on land (e.g. geysers, hot springs) and on the seafloor at Mid-Ocean Ridges (MOR), back arc basins and subduction zones. 
During hydrothermal circulation, seawater heats up and interacts with rocks in the hot Earth's crust and mantle. Hydrothermal systems are the places where this modified seawater is expelled as hydrothermal fluids. Waterrock interactions generate gases $\left(\mathrm{CH}_{4}, \mathrm{H}_{2}, \mathrm{H}_{2} \mathrm{~S}\right)$, whereas, major and minor elements such as Fe, Mn, $\mathrm{Ca}, \mathrm{Li}, \mathrm{K}, \mathrm{Na}, \mathrm{Cl}, \mathrm{Si}$ are exchanged between rocks and water. These chemical entities may dissolve in the fluids or precipitate (metal oxide particle). Concentrations in the aqueous phase vary depending on lithologies (rock assemblages), processes that occur during hydrothermal circulation and physico-chemical conditions. For example, major variations in the salinity of the fluids are thought to be due to phase separation [15-18]. Although the inorganic geochemistry of hydrothermal fluids is quite well documented and understood, the study of their organic geochemistry is near its beginning. This is mainly due to sampling and extraction difficulties. Indeed, hydrothermal fluids can be defined as an extremely complex and unusual matrix in which organic compounds are dissolved. The number of samples is limited and collected volumes are small because sampling of hydrothermal fluids is laborious. An extraction method capable of recovering a wide range of organic compounds from small sample volumes of a complex matrix is required and this is a real challenge.

Various sample preparation techniques are available to extract and concentrate analytes from liquids: solid phase extraction (SPE) [19], solid phase microextraction (SPME) [20], membrane extraction with a sorbent interface (MESI) [21], liquid-liquid extraction (LLE) [22], supercritical fluid extraction (SFE) [23], pressurized fluid extraction (PFE) [24] and microwave-assisted solvent extraction [25] to cite a few. The most used techniques for extraction of analytes in liquids are based on LLE or SPE. Over the years, they have proven their efficiency in terms of quantification and most standardised analytical methods use them [19]. However, both techniques involve multiple time-consuming operations. In particular, SPE requires a tedious filtration step to remove suspended particles present in the matrix. The numerous preparation steps associated with SPE extraction multiply sources and risks of contamination. For instance, SPE sorbents and especially polymeric ones constitute major sources of contaminants due to plastics bleeding [26]. Finally LLE uses large amounts of solvents. All these drawbacks cause particular interferences when dealing with small sample volumes containing relatively low amounts ( $\sim \mathrm{ppb})$ of unknown organic compounds dissolved in a complex matrix. Therefore these methods are not the most suitable for the analysis of organic compounds in hydrothermal fluids.

The analysis of volatile and semivolatile organic compounds in aqueous solutions using Stir Bar Sorptive Extraction (SBSE) as the extraction step is gaining acceptance in a wide variety of applications in the environmental (e.g., water analyses), food and biomedical fields [27]. The SBSE is a robust, efficient and convenient technology. It requires minimal sample volumes, the recovery rate is higher than $90 \%$ for most nonpolar compounds and $100 \%$ of the organic matter sorbed on a stir bar is analysed. The few contaminants associated with SBSE are methylcyclosiloxanes and readily identifiable. The method allows gas chromatographic analysis of organic compounds in aqueous matrices faster than with conventional techniques, omitting time-costly preparation steps and solvents. In addition, the technique has shown great potential to extract organic compounds even from complex matrices (e.g., waste waters, beverages, biological fluids) and to achieve exceedingly low detection limits, under optimised conditions, by being times more sensitive than direct SPME $[28,29]$. For example, Ochiai and Nakamura [30] measured sub-part per trillion (sub-ppt) levels of off-flavor compounds in drinking water. In seawater, polyaromatic hydrocarbons (PAHs) have been detected down to the sub-ppt levels [31] and Pérez-Carrera et al. [32] reported limits of detection (LOD) of the order of the ppt for PCBs. León et al. [33] obtained LOD in the range of 0.04 to $11 \mathrm{ppt}$ for semivolatile organic compounds $\left(2<\operatorname{LogK}_{\mathrm{o} / \mathrm{w}}<7.66\right.$, see explanation in the next paragraph) in salted tap water. Nevertheless, SBSE, like any other analytical method, has some limitations for extraction of certain compounds and the attainment of such low LOD may require further sample preparation, e.g., $\mathrm{pH}$ adjustment, back extraction or derivatisation [34].

As mentioned in a review on SBSE theory and applications [27], SBSE is by nature an equilibrium technique based on the partitioning of solutes between a polymer phase (PolyDiMethylSiloxane (PDMS)) and the aqueous matrix. This polymer is in a liquid-like state at room temperature, resulting in the retention of the analytes by dissolution into the bulk of the PDMS (this phenomenon is called sorption) rather than by adsorption on a surface which is the retention process involved in other extraction techniques. The partition equilibrium is correlated with the octanol-water partition coefficient $\left(\mathrm{K}_{\mathrm{o} / \mathrm{w}}\right)$ which can be defined by equation (1):

$$
\begin{aligned}
\mathrm{K}_{\mathrm{O} / \mathrm{W}} \approx \mathrm{K}_{\mathrm{PDMS} / \mathrm{W}} & =\mathrm{C}_{\mathrm{SBSE}} / \mathrm{C}_{\mathrm{W}} \\
& =\left(\mathrm{m}_{\mathrm{SBSE}} / \mathrm{m}_{\mathrm{W}}\right) \times\left(\mathrm{V}_{\mathrm{W}} / \mathrm{V}_{\mathrm{SBSE}}\right)
\end{aligned}
$$

where $C_{S B S E}$ and $C_{W}$ are the analyte concentration in the SBSE and the water phase, respectively, $\mathrm{m}_{\mathrm{SBSE}}$ and $\mathrm{m}_{\mathrm{W}}$ are the mass of analyte in the SBSE and the water phase, respectively and $\mathrm{V}_{\text {SBSE }}$ and $\mathrm{V}_{\mathrm{W}}$ are the volume of PDMS and water phase, respectively.

The retention and the recovery rate of a molecule mainly depend on $\mathrm{K}_{\mathrm{o} / \mathrm{w}}$ and on the sample to PDMS volumes ratio 


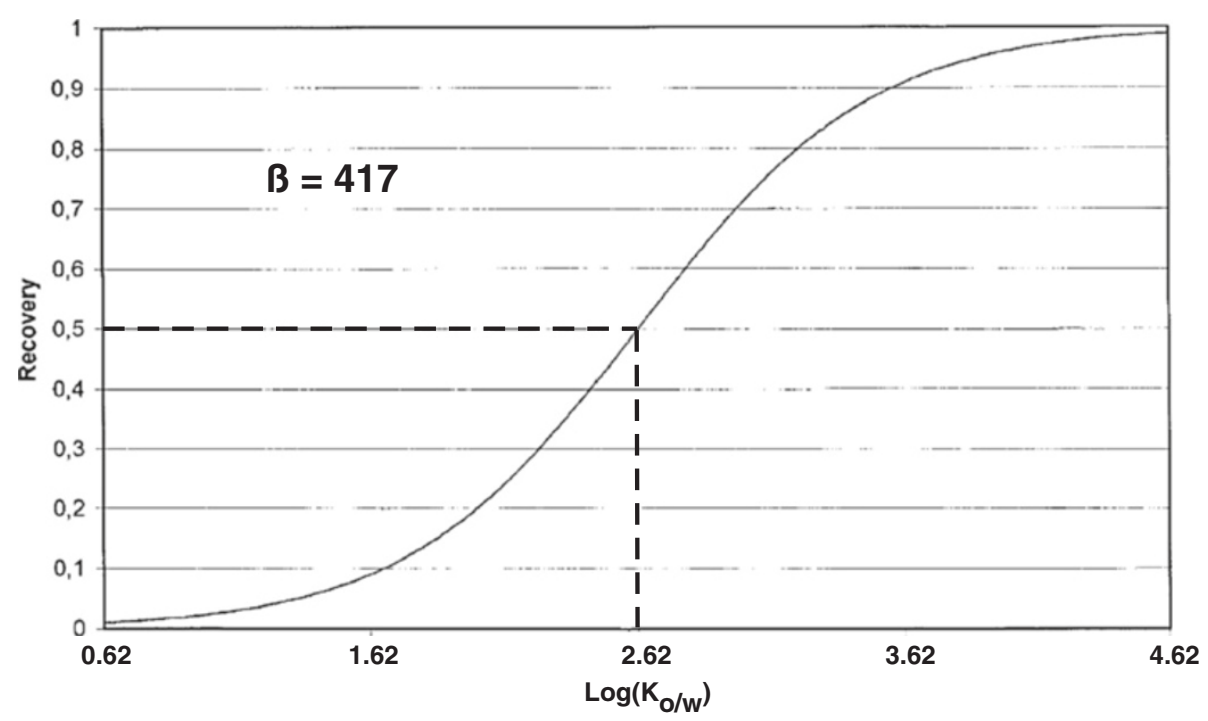

Figure 1 Modified after Baltussen et al. [28]. Recovery as a function of the octanol-water partitioning constant $\log \left(\mathrm{K}_{\mathrm{o} / \mathrm{w}}\right)$.

$(\beta)$, even though concentration of analytes, $\mathrm{pH}$, polarity of the matrix and extraction time have some effect $[27,35]$. To a lesser extent, analytical parameters such as desorption flow, CIS initial temperature and CIS splitless time may also affect the retention and recovery rate of a compound [36]. Using $\beta$, equation (1) can be restated as:

$$
\mathrm{K}_{\mathrm{O} / \mathrm{W}} / \beta=\mathrm{m}_{\mathrm{SBSE}} / \mathrm{m}_{\mathrm{W}}=\mathrm{m}_{\mathrm{SBSE}} /\left(\mathrm{m}_{0}-\mathrm{m}_{\mathrm{SBSE}}\right)
$$

where $\mathrm{m}_{0}$ is the total amount of analyte originally present in the water sample. For a more detailed theoretical study, we urge the reader to refer to a paper by Baltussen et al. [28] who have been pioneers in the SBSE method development.

In our case $\beta=417\left(\mathrm{~V}_{\mathrm{W}}=10 \mathrm{~mL}\right.$ and $\left.\mathrm{V}_{\mathrm{SBSE}}=24 \mu \mathrm{L}\right)$ and this corresponds to a recovery $>50 \%$ for compounds with $a K_{o / w}>2.62$ in pure water (Figure 1). However, the partition coefficients may vary with the $\mathrm{pH}$; typically for polar compounds [37]. Also, the presence of dissolved salts and gases, as well as particulates to which organic molecules can bind, are likely to affect the way compounds partition between PDMS and hydrothermal fluids.

Table 1 Summary of the groups of compounds detected $(+)$ and not detected (nd) in fluids from the Rainbow hydrothermal field over 3 years and in the deep seawater extract

\begin{tabular}{|c|c|c|c|c|c|}
\hline Compound & $\log \left(K_{o / w}\right)$ & 2005 & 2007 & 2008 & Deep seawater \\
\hline n-alkanes $\left(C_{9-19}\right)$ & $5.5-8.2$ & $\mathrm{C}_{9-14}$ & $C_{11}$ & $C_{10}$ & $C_{11}$ \\
\hline branched saturated alkanes $\left(C_{9-12}\right)$ & $5.0-6.8$ & + & nd & + & nd \\
\hline cycloalkanes $\left(C_{9-11}\right)$ & $4.9-6.0$ & + & nd & nd & one $\mathrm{C}_{9}$ \\
\hline phenol & 1.5 & + & nd & + & nd \\
\hline toluene & 2.7 & + & + & + & + \\
\hline ethylbenzene & 3.2 & + & nd & + & nd \\
\hline xylene & $3.2^{*}$ & + & nd & + & + \\
\hline styrene & 2.7 & + & + & + & + \\
\hline other alkylated benzenes $\left(C_{9-12}\right)$ & $3.7-5.0$ & nd & $?$ & $?$ & one $\mathrm{C}_{9} \mathrm{H}_{12}$ \\
\hline naphthalene & 3.4 & + & + & + & + \\
\hline methyl and dimethyl naphthalenes & $>3$ & + & + & + & nd \\
\hline PAHS $\left(C_{12-16}\right)$ & $4.2-5.2$ & + & + & + & nd \\
\hline n-fatty acids $\left(\mathrm{C}_{8-18}\right)$ & $3.4-8.2$ & $C_{9-18}$ & $C_{8-10}$ & $C_{9-16}$ & $\mathrm{C}_{6}$ and $\mathrm{C}_{14-16}$ \\
\hline
\end{tabular}

* [38].

(?) stands for compounds for which further investigation is needed to confirm their presence. Results were identical for the two samples in 2007 with respect to the compounds listed in this table, therefore it appears only one column for 2007. $C_{n}$ is the carbonated chain length of the identified compounds. Additionally, ranges of $\log \left(\mathrm{K}_{\mathrm{o} / \mathrm{w}}\right)$ values at $25^{\circ} \mathrm{C}$ for pure water are given. These values are meant to give a rough estimate only. The reader should bear in mind that the partition between seawater or hydrothermal fluids and PDMS will somewhat differ from these values. Precise identification of isomers was not possible without the use of synthetic standards so that ranges of values have been determined based on $\log \left(\mathrm{K}_{\mathrm{o} / \mathrm{w}}\right)$ values for compounds with the same raw formula. Values were obtained from the SciFinder ${ }^{\circledR}$ data base. 


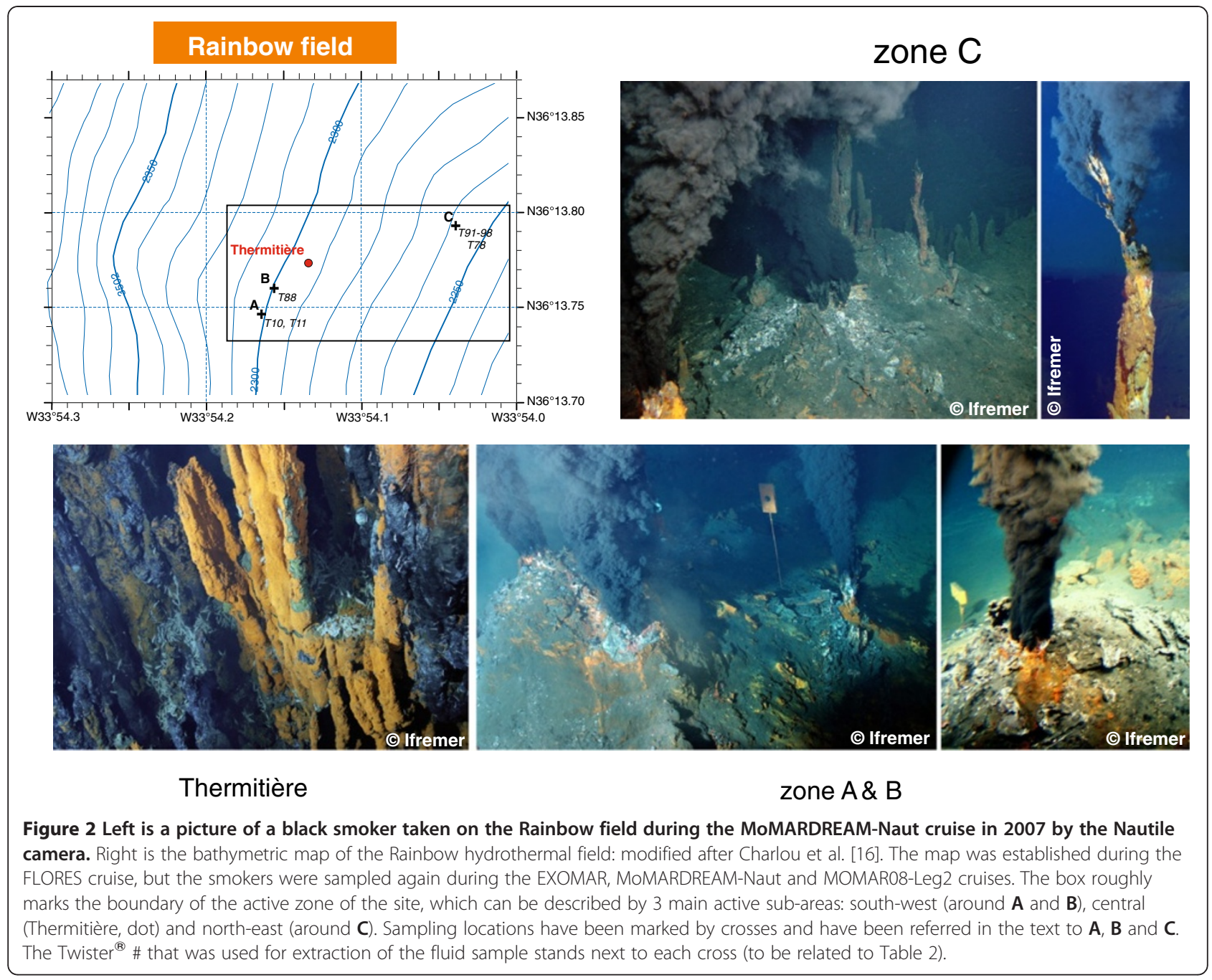

As such, the recovery rate in hydrothermal fluids may deviate somewhat from that in pure water. Nevertheless, we provide in Table 1 an estimate of the range of $\log \left(\mathrm{K}_{\mathrm{o} / \mathrm{w}}\right)$ values in pure water for the type of compounds that are very likely inherent to hydrothermal fluids. In this study, we show that SBSE - Thermal Desorption - Gas Chromatography - Mass Spectrometry (TD-GC-MS) is an effective and reliable method capable of isolating a wide range of organic molecules from small sample volumes of the complex matrix that are hydrothermal fluids. This

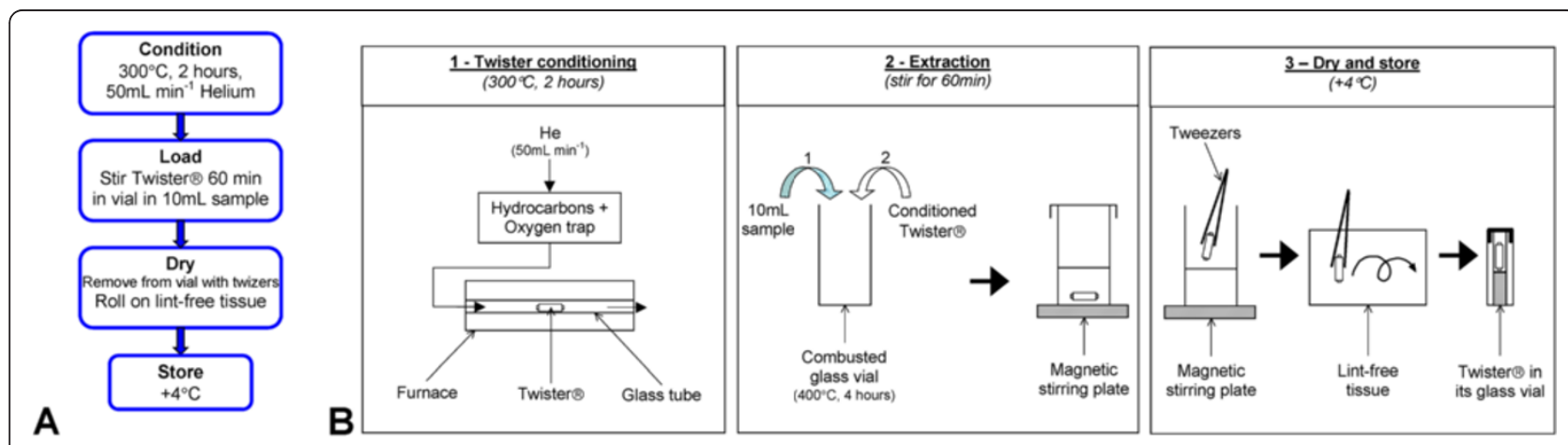

Figure 3 Summary diagram of the SBSE procedure (A) and schematic representation of the sample preparation step (B). 
Table 2 General features of the samples used in this work

\begin{tabular}{ccccccccc}
\hline Year & Location & Sample name & Twister $^{\circledR} \#$ & Depth $(\boldsymbol{m})$ & $\boldsymbol{p H}$ & $\boldsymbol{T}\left({ }^{\circ} \mathbf{C}\right)$ & $\boldsymbol{H}_{\mathbf{2}} \mathbf{S}(\mathbf{m M})$ & $\boldsymbol{C r}(\mathbf{m M})$ \\
\hline 2005 & A & EXO-D6-Ti1 & T10 \& T11 & 2306 & 3.79 & 353 & 0.963 & 774 \\
2007 & B & MAD-D8-Ti1D & T88 & 2305 & 3.36 & 350 & - & 754 \\
2007 & C & MAD-D6-Ti2G & T78 & 2265 & 3.23 & 353 & - & 761 \\
2008 & C & MOM-D4-Ti3 & T91-T98 & 2258 & 3.18 & 360 & - & 716 \\
$2005-8$ & - & Deep seawater & - & $2230-90$ & 7.84 & 2 & $<0.1$ & 547 \\
\hline
\end{tabular}

For location refer to Figure 2.

Typical concentrations in deep seawater are given for reference. A deep seawater sample was collected each year outside of the active zone (outside the box on Figure 2) and the values are averages of those 3 samples.

technique is therefore suitable and essential for the study of the organic geochemistry of hydrothermal fluids. We demonstrate this by applying SBSE to the analyses of fluids from the Rainbow ultramafic-hosted hydrothermal field ( $36^{\circ} 14^{\prime} \mathrm{N}$, Mid-Atlantic Ridge).

\section{Experimental}

\section{Features of the study area}

The Rainbow site is an unsedimented hydrothermal field located on the Mid-Atlantic Ridge (MAR), south of the Azores, at $36^{\circ} 14^{\prime} \mathrm{N}, 33^{\circ} 54^{\prime} \mathrm{W}$ and at $2300 \mathrm{~m}$ depth [39]. It is located at the intersection of the non-transform fault system and the ridge faults, on the west-facing flank of the Rainbow ridge at the northeastern corner of the south Azores Mid-Atlantic Ridge (AMAR) segment. The field measures is about $250 \mathrm{~m}$ (east-west) by $60 \mathrm{~m}$ (north-south) and consists of three qualitatively distinct active areas (Figure 2): Thermitière, an organ pipe-like structure with both hot and diffuse fluids that hosts most of the biota, the north-east zone (C on Figure 2), which consists of very active short black smokers and the south-west zone (A, B on Figure 2), which is less active, with a lot of old chimneys and a few tall candelabrum-like active chimneys. The Rainbow field is located on peridotite-rich mantle outcrops that are associated with emission of large amounts of $\mathrm{CH}_{4}$ [40]. These peridotites are undergoing serpentinisation, leading to production of a large amount of $\mathrm{H}_{2}[9,16]$. The

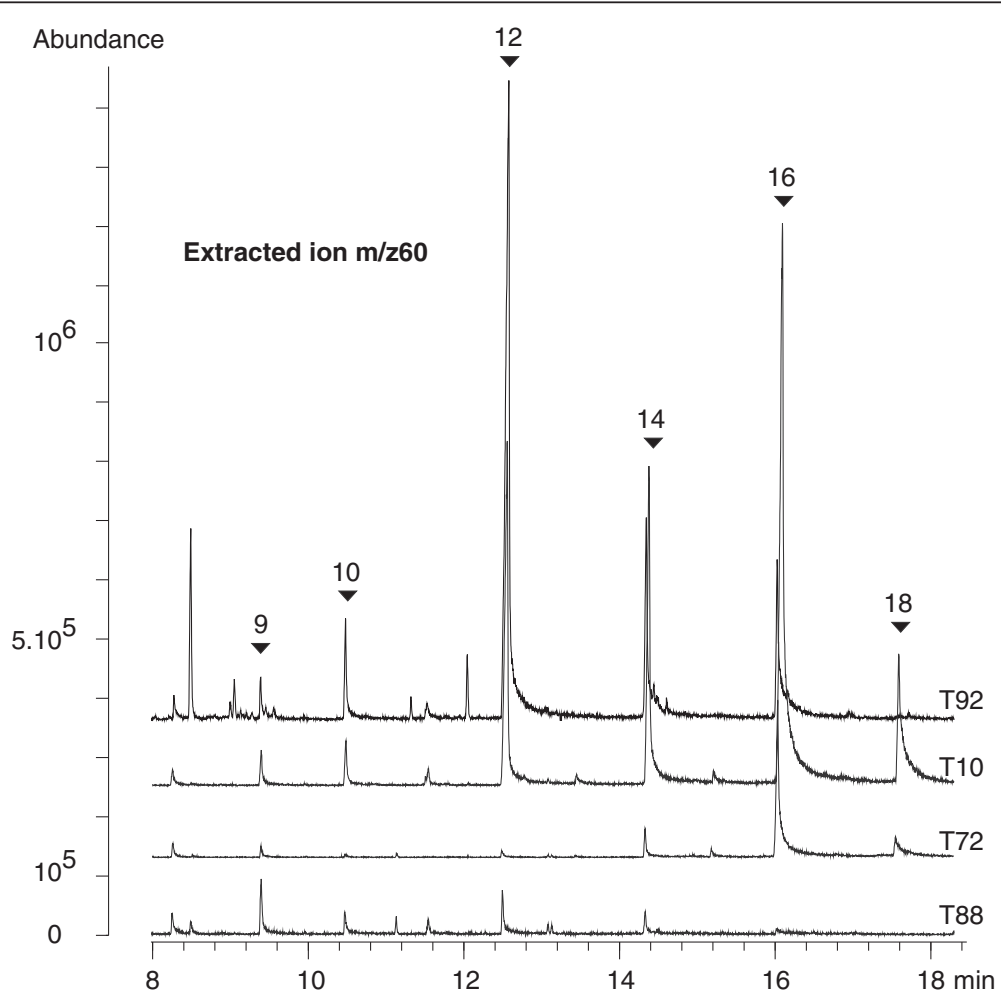

Figure 4 Extracted ion chromatograms at the qualifier ions $m / z 60$ of the SBSE-TD-GC-MS analysis of 3 hydrothermal fluid samples (T10, T88, T92) and a deep seawater sample (T72). Top to bottom: T92, T10, T72 and T88. Description of these samples is found in Table 2. n-Carboxylic acids peaks are pointed out (full triangle) with their respective carbon number standing above. Rt are given in Table 3. 
temperature of the fluids is around $360^{\circ} \mathrm{C}$ leading to phase separation in the subseafloor [39,41]. High chlorinity $\left(780 \mathrm{mmol} \mathrm{kg}^{-1}\right)$, low $\mathrm{pH}(\mathrm{pH}=3-4)$, high concen-

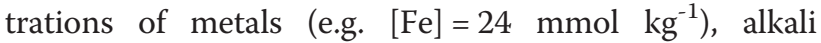
metals and alkaline earth metals [41], low concentration of dissolved $\mathrm{SiO}_{2}$, and high levels of dissolved hydrogen $\left(16 \mathrm{mmol} \mathrm{kg}{ }^{-1}\right)$ and methane $\left(2.5 \mathrm{mmol} \mathrm{kg}{ }^{-1}\right)[16,40]$ characterise the inorganic geochemistry of the Rainbow fluids. Finally there have been reports that hydrocarbons and oxidized organic compounds are dissolved in the Rainbow fluids $[12,13]$.

\section{Sample collection and preparation}

All glassware used was pre-combusted at $400^{\circ} \mathrm{C}$ for 4 hours to remove any trace of organic matter. The commercial stir bars (Twisters ${ }^{\circledR}$ ) used in this study consist of a magnetic rod in a tubular glass housing coated with $24 \mu \mathrm{L}$ PDMS (length $=10 \mathrm{~mm}$, film thickness $=0.5 \mathrm{~mm})$. They were purchased from Gerstel GmbH \& Co. KG (Mülheim an der Ruhr, Germany). Twisters $^{\circledR}$ were conditioned prior to use by thermal desorption at $300^{\circ} \mathrm{C}$ for 2 hours under a purified helium (He) flow (50 mL min ${ }^{-1}$ ) (Figure 3). For each batch of conditioned Twisters ${ }^{\circledR}$ one was kept as a dry blank reference.

Hot fluids of the Rainbow ultramafic-hosted hydrothermal field and deep seawater were collected in titanium syringes using the same procedure. Sampling was conducted by the ROV Victor 6000 during the EXOMAR (2005) and MOMAR08-Leg2 (2008) [42] cruises

Table 3 Retention times ( $R t_{\text {stds }}$ ) of $C_{8: 0}-C_{20: 0}$ carboxylic acids obtained by SBSE-TD-GC-MS analyses of a standard mixture $(50 \mu \mathrm{g} / \mathrm{L})$

\begin{tabular}{lccc}
\hline Compounds & Molecular formula & $\boldsymbol{R t}_{\text {stds }}(\mathbf{m i n})$ & $\boldsymbol{R t}_{\text {fluids }}$ (min) \\
\hline octanoic acid & $\mathrm{C} 8 \mathrm{H} 16 \mathrm{O} 2$ & 8.30 & $8.24 \dagger$ \\
nonanoic acid & $\mathrm{C} 9 \mathrm{H} 18 \mathrm{O} 2$ & 9.47 & $9.43^{*}$ \\
decanoic acid & $\mathrm{C} 10 \mathrm{H} 20 \mathrm{O} 2$ & 10.61 & $10.52^{*}$ \\
undecanoic acid & $\mathrm{C} 11 \mathrm{H} 22 \mathrm{O} 2$ & 11.68 & - \\
dodecanoic acid & $\mathrm{C} 12 \mathrm{H} 24 \mathrm{O} 2$ & 12.67 & $12.58^{*}$ \\
tridecanoic acid & $\mathrm{C} 13 \mathrm{H} 26 \mathrm{O} 2$ & 13.59 & - \\
tetradecanoic acid & $\mathrm{C} 14 \mathrm{H} 28 \mathrm{O} 2$ & 14.44 & $14.41^{*}$ \\
pentadecanoic acid & $\mathrm{C} 15 \mathrm{H} 30 \mathrm{O} 2$ & 15.24 & $15.23+$ \\
hexadecanoic acid & $\mathrm{C} 16 \mathrm{H} 32 \mathrm{O} 2$ & 16.02 & $16.12^{*}$ \\
heptadecanoic acid & $\mathrm{C} 17 \mathrm{H} 34 \mathrm{O} 2$ & 16.78 & - \\
octadecanoic acid & $\mathrm{C} 18 \mathrm{H} 36 \mathrm{O} 2$ & 17.65 & $17.61^{*}$ \\
nonadecanoic acid & $\mathrm{C} 19 \mathrm{H} 38 \mathrm{O} 2$ & 18.27 & - \\
eicosanoic acid & $\mathrm{C} 20 \mathrm{H} 40 \mathrm{O} 2$ & - & - \\
\hline Detection of the compound & was acheved using & & - \\
\hline
\end{tabular}

Detection of the compounds was achieved using ions $\mathrm{m} / \mathrm{z} 60$ and 73 . The NIST08 library was used for identification. Retention times ( $\mathrm{Rt}_{\text {fluids }}$ ) obtained in hydrothermal fluids are given for direct comparison: * This study, + [13]. and by the Nautile during the MOMARDREAM-Naut (2007) cruise [43]. All cruises were made under the auspices of Ifremer, France. Hot fluid samples were taken as deep as possible within black smokers to minimise seawater mixing. Deep seawater samples were taken in the vicinity of the Rainbow field where hydrothermal input could be discounted. Table 2 lists the samples used in
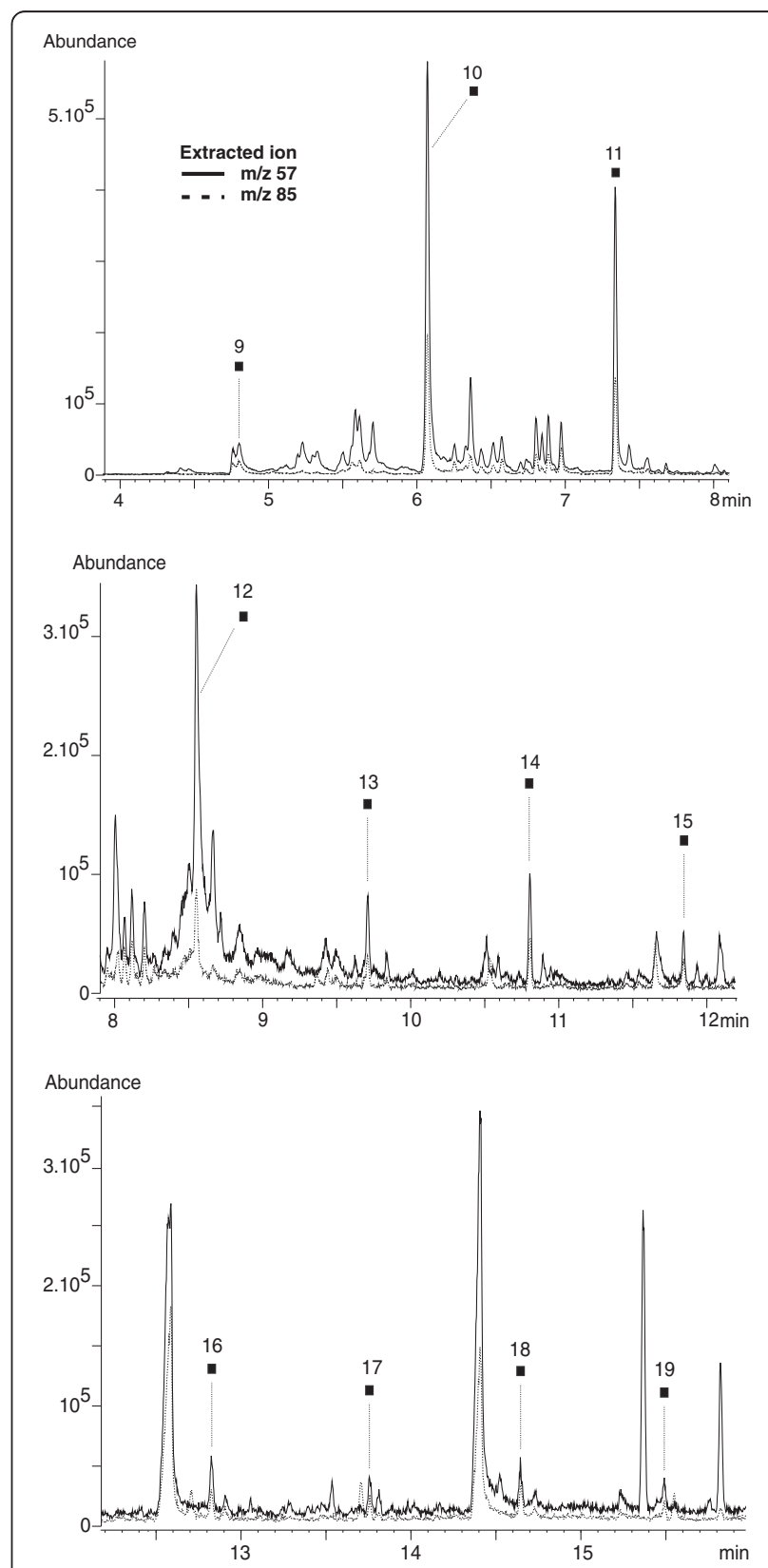

Figure 5 Extracted ion chromatograms at the qualifier ions $\mathrm{m} / \mathrm{z}$ 57 (full line) and $m / z 85$ (dashed line) of the SBSE-TD-GC-MS of the $\mathbf{2 0 0 5}$ hydrothermal fluid extract (Table 2). n-Alkanes were only detected that year. The corresponding peaks are pointed out with their respective carbon number standing above. Rt are given in Table 4. 
Table 4 Retention times ( $R t_{\text {stds }}$ ) of $C_{9}-C_{20}$-alkanes obtained by SBSE-TD-GC-MS analyses of a standard mixture $(10 \mu \mathrm{g} / \mathrm{L})$

\begin{tabular}{lccc}
\hline Compounds & Molecular formula & $\boldsymbol{R t}_{\text {stds }}$ (min) & $\boldsymbol{R t}_{\text {fluids }}$ (min) \\
\hline nonane & $\mathrm{C} 9 \mathrm{H} 20$ & 4.75 & 4.76 \\
decane & $\mathrm{C} 10 \mathrm{H} 22$ & 6.01 & 6.05 \\
undecane & $\mathrm{C} 11 \mathrm{H} 24$ & 7.28 & 7.32 \\
dodecane & $\mathrm{C} 12 \mathrm{H} 26$ & 8.49 & 8.52 \\
tridecane & $\mathrm{C} 13 \mathrm{H} 28$ & 9.65 & 9.70 \\
tetradecane & $\mathrm{C} 14 \mathrm{H} 30$ & 10.74 & 10.79 \\
pentadecane & $\mathrm{C} 15 \mathrm{H} 32$ & 11.77 & 11.81 \\
hexadecane & $\mathrm{C} 16 \mathrm{H} 34$ & 12.77 & 12.81 \\
heptadecane & $\mathrm{C} 14 \mathrm{H} 36$ & 13.69 & 13.74 \\
octadecane & $\mathrm{C} 18 \mathrm{H} 38$ & 14.57 & 14.62 \\
nonadecane & $\mathrm{C} 19 \mathrm{H} 40$ & 15.41 & 15.47 \\
eicosane & $\mathrm{C} 20 \mathrm{H} 42$ & 16.21 & -
\end{tabular}

Detection of the compounds was achieved using ions $\mathrm{m} / \mathrm{z} 57$ and 85 . The NIST08 library was used for identification. Retention times ( $\mathrm{Rt}_{\text {fluids }}$ ) obtained in hydrothermal fluids samples of this study are given for direct comparison.

this study and gives their general characteristics, whereas Figure 2 shows the distribution of the sampling locations over the Rainbow hydrothermal field. Only an aliquot of the total sample volume could be dedicated to organic geochemistry. As soon as the syringes were recovered, $10 \mathrm{~mL}$ aliquots of fluid samples were accurately measured using a pipette and transferred from the titanium syringes into glass vials where the conditioned Twisters ${ }^{\circledR}$ were added and allowed to stir for $60 \mathrm{~min}$ at $300 \mathrm{rpm}$. Twisters ${ }^{\circledR}$ were then removed, dried on lint-free tissue and stored in their airtight glass vials at $+4^{\circ} \mathrm{C}$ until analysis by TD-GC-MS. A summary of these operations is shown schematically in Figure 3.

\section{Synthetic standards}

We chose for this preliminary study to focus on the groups of compounds that were the most relevant to hydrothermal organic geochemistry: n-alkanes, linear fatty acid and aromatic hydrocarbons [13,44]. Other aliphatic hydrocarbons (branched and cyclic) have been reported in hydrothermal fluids and would also be of interest, but compounds of these homologous series have mass spectra that are too similar to be accurately identified without the use of standards of individual compounds. Individual custom standards are very expensive. Moreover these additional hydrocarbons were not essential to show the suitability of SBSE-TD-GC-MS for the analysis of hydrothermal fluids. Therefore we considered such a purchase unnecessary.

Custom mixtures were purchased from LGC standards SARL, Molsheim, France: $\mathrm{C}_{8}-\mathrm{C}_{20}$ linear fatty acids in isooctane at $1 \mathrm{mg} / \mathrm{mL} ; \mathrm{C}_{9}-\mathrm{C}_{20}$ n-alkanes in $\mathrm{MeOH}$; monoaromatic hydrocarbons (BTEX) in $\mathrm{MeOH}$ at $200 \mu \mathrm{g} / \mathrm{mL}$; PAHs in $\mathrm{MeOH}$ at $1 \mathrm{mg} / \mathrm{mL}$. Three separate solutions were prepared by spiking MQ water (18.2 M $\Omega$ ) with fatty acids $(50 \mu \mathrm{g} / \mathrm{L}) ; \mathrm{n}$-alcanes $(10 \mu \mathrm{g} / \mathrm{L}) ;$ PAHs and BTEX $(10 \mu \mathrm{g} / \mathrm{L})$. Extraction was performed using to the same procedure as for the hydrothermal fluids (see $\mathbb{S}$ "Sample collection and preparation").

\section{Instrumentation and analytical conditions}

Analyses of the stir bars were performed by TD-GC-MS. The Twisters ${ }^{\circledR}$ were thermally desorbed in the thermal desorption system (TDS-2, GERSTEL GmbH E Co. KG, Mülheim an der Ruhr, Germany) mounted on a 6890 Agilent GC (Agilent Technologies, Little Falls, DE, USA) equipped with a 5973 quadrupole mass spectrometer detector (MSD). The TDS was coupled to a cooled injection system (CIS4, GERSTEL GmbH \& Co. KG, Mülheim
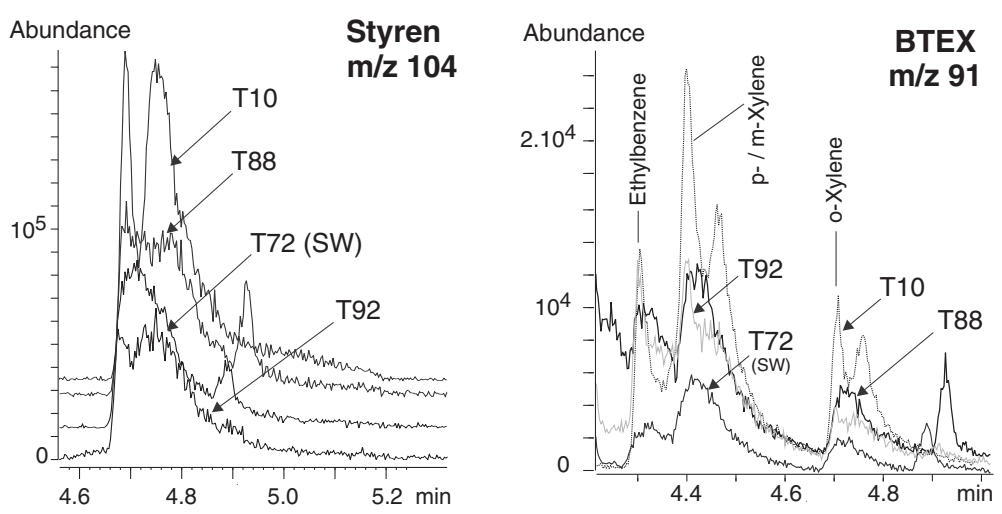

Figure 6 Zooms of extracted ion chromatograms at the qualifier ion $m / z 104$ (left) and $m / z 91$ (right) of the SBSE-TD-GC-MS analysis of 3 hydrothermal fluid samples (T10, T88, T92) and a deep seawater sample (T72). Arrows point out their respective traces. On the right panel, T92 and T10 signals are represented in dashed line while T72 and T88 appear in full line. The styrene peak elutes at 4.71 min (left) and the other BTEX in the $4.31-4.71$ min range (right). Refer to Table 2 and Table 5 for description of the samples and Rt values. 

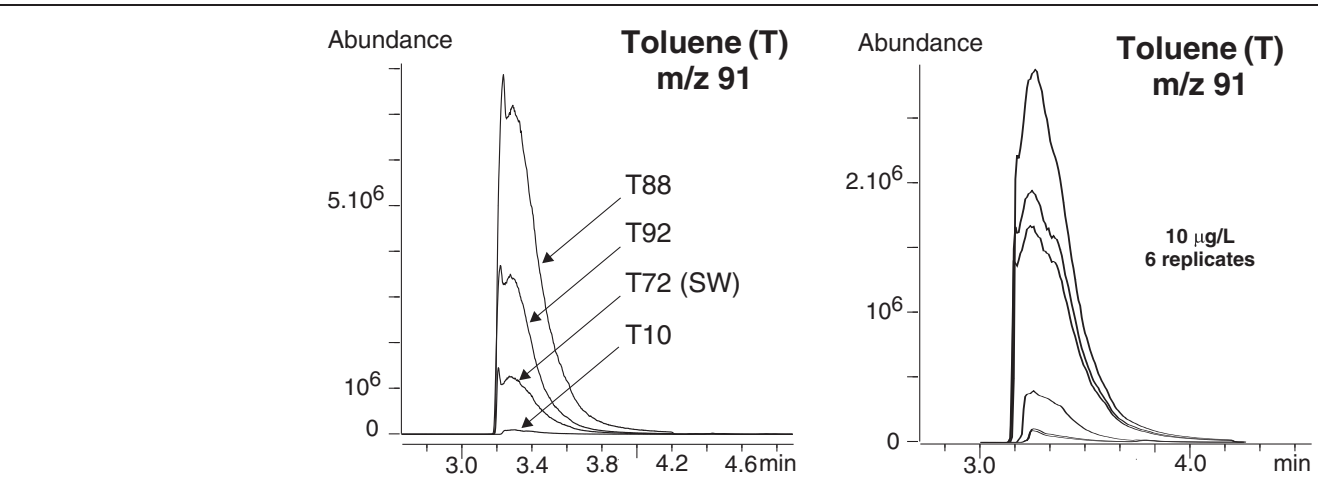

Figure 7 Zooms of extracted ion chromatograms at the qualifier ion $\mathrm{m} / \mathrm{z} 91$ of the SBSE-TD-GC-MS analysis of 3 hydrothermal fluid samples (T10, T88, T92) and a deep seawater sample (T72) (left panel); and 6 replicates of MQ water spiked with toluene at $10 \mu \mathrm{g} / \mathrm{L}$ (right panel). On the left panel, arrows point out the respective traces of natural samples. Refer to Table 2 and Table 5 for description of the samples and Rt values.

an der Ruhr, Germany) for cryofocusing the analytes prior to their transfer onto the column. Liquid nitrogen was used to cool and maintain the CIS at $-100^{\circ} \mathrm{C}$ while the Twister $^{\circledR}$ was desorbed in the TDS in the splitless mode at $300^{\circ} \mathrm{C}$ for 5 min under He flow. The CIS was then heated to $250^{\circ} \mathrm{C}$. Separation was achieved on an HP5-MS (Agilent Technologies, Little Falls, DE, USA) capillary column $(30 \mathrm{~m} \times 0.25 \mathrm{~mm}$ i.d. $\times 0.25 \mu \mathrm{m}$ film thickness). The GC column temperature was held first at $40^{\circ} \mathrm{C}$ for $1 \mathrm{~min}$, then ramped from 40 to $320^{\circ} \mathrm{C}$ at $12^{\circ} \mathrm{C} \mathrm{m^{-1 }}$ and held at $320^{\circ} \mathrm{C}$ for $2 \mathrm{~min}$. Helium was used as carrier gas with a flow of $1.2 \mathrm{~mL} \mathrm{~min}^{-1}$. The mass spectrometer was operated simultaneously in full scan and selected-ion monitoring (SIM) modes for the analysis of standard solutions, whereas hydrothermal fluids samples could only be analysed in full scan mode. Electron ionisation mass spectra were recorded in the 10 to $500 \mathrm{amu}$ range at $70 \mathrm{eV}$ ionisation energy. The dwell time was adjusted in the SIM mode to obtain 2 to 3 cycles / sec. Data were acquired and processed by the Chemstation software. Retention times (Rt) of the targeted compounds were determined with the help of the NIST08 library, using both the full scan and SIM chromatograms of the standard solutions. Unequivocal identification of individual organic compounds in hydrothermal fluids was possible using both the Rt of the standards and extracted ion chromatograms.

\section{Results and discussion}

Identification of compounds in hydrothermal fluids using standard mixtures

Konn et al. [13], successfully identified organic compounds in several hydrothermal fluid samples based on comparison with the NIST02 library associated with consistent Rt. The present study confirms these early pioneering results using standard mixtures for n-carboxylic acids, n-alkanes as well as mono- and poly- aromatic hydrocarbons. Simultaneous analyses of standard solution extracts in full scan and SIM mode enabled accurate determination of the retention times (Rt) of the targeted compounds. Retention times have been proposed for these compounds in hydrothermal fluids based on previous studies $[13,44]$ and the NIST08 library (this study). Retention times values were generally very similar in standard solutions and hydrothermal fluids, which confirms that our previous peak assignment was correct. Chromatograms of hydrothermal fluids usually differed from those of the standard solutions. These variations are unlikely to be artifacts due to matrix differences because the extraction rate of compounds of a homologous series

Table 5 Retention times ( $\mathbf{R t}_{\text {stds }}$ ) of monoaromatic hydrocarbons obtained by SBSE-TD-GC-MS analyses of a standard mixture (BTEX at $10 \mu \mathrm{g} / \mathrm{L}$ )

\begin{tabular}{lccc}
\hline Compounds & Molecular formula & $\boldsymbol{R t}_{\text {stds }}(\mathbf{m i n})$ & $\boldsymbol{R t}_{\text {fluids }}(\mathbf{m i n})$ \\
\hline toluene (T) & $\mathrm{C} 7 \mathrm{H} 8$ & 3.28 & 3.26 \\
ethylbenzene & $\mathrm{C} 8 \mathrm{H} 10$ & 4.33 & 4.34 \\
p-xylene / m-xylene & $\mathrm{C} 8 \mathrm{H} 10$ & 4.45 & 4.43 \\
o-xylene & $\mathrm{C} 8 \mathrm{H} 10$ & 4.74 & 4.71 \\
styrene & $\mathrm{C} 8 \mathrm{H} 8$ & 4.74 & 4.71 \\
isopropylbenzene & $\mathrm{C} 9 \mathrm{H} 12$ & 5.10 & - \\
n-propylbenzene & $\mathrm{C9H12}$ & 5.49 & - \\
1,3,4-trimethylbenzene & $\mathrm{C} 9 \mathrm{H} 12$ & 5.61 & - \\
tert-butylbenzene & $\mathrm{C} 10 \mathrm{H} 14$ & 5.96 & - \\
1,3,5-trimethylbenzene & $\mathrm{C} 9 \mathrm{H} 12$ & 6.00 & - \\
sec-butylbenzene & $\mathrm{C10H14}$ & 6.21 & - \\
paraisopropyltoluene & $\mathrm{C} 10 \mathrm{H} 14$ & 6.39 & - \\
n-butylbenzene & $\mathrm{C} 10 \mathrm{H} 14$ & 6.81 & - \\
\hline
\end{tabular}

Detection of the compounds was achieved using ions $\mathrm{m} / \mathrm{z}$ 91, 103.9, 104.9, 120 and 133.9. The NIST08 library was used for identification. Retention times ( $\mathrm{Rt}_{\text {fluids }}$ ) obtained in hydrothermal fluids samples of this study are given for direct comparison. 
should be affected in the same way. Our results suggested that the distribution patterns of each group of compounds in hydrothermal fluids are specific. Such patterns are likely the result of the particular geochemical processes controlling the formation and dissolution of organic compounds in hydrothermal fluids.

\section{n-Carboxylic acids}

Peaks of underivatized fatty acid have a tendency to tail on a HP5-MS column due to the polarity of the compounds (Figure 4). Therefore peaks may be easily detected by the naked eye. However, detection of n-fatty acid peaks was best achieved by targeting ion $\mathrm{m} / \mathrm{z} 60$ (major) and 73 (confirmation) in the standard solution and by extracting ion $\mathrm{m} / \mathrm{z} 60$ in hydrothermal fluid samples. This major ion is characteristic of carboxylic acids and forms via a McLafferty rearrangement [45]. The whole series of $n$-fatty acids $\left(\mathrm{C}_{8: 0}-\mathrm{C}_{18: 0}\right)$ was detected in the standard mixture. The best response was obtained for $\mathrm{C}_{9: 0}-\mathrm{C}_{16: 0}$ compounds, whereas $\mathrm{C}_{8: 0}$ and $\mathrm{C}_{17: 0}-\mathrm{C}_{19: 0}$ had a much higher LOD. This can be explained by the low $\mathrm{K}_{\mathrm{o} / \mathrm{w}}$ value of shorter chain fatty acids and the weak

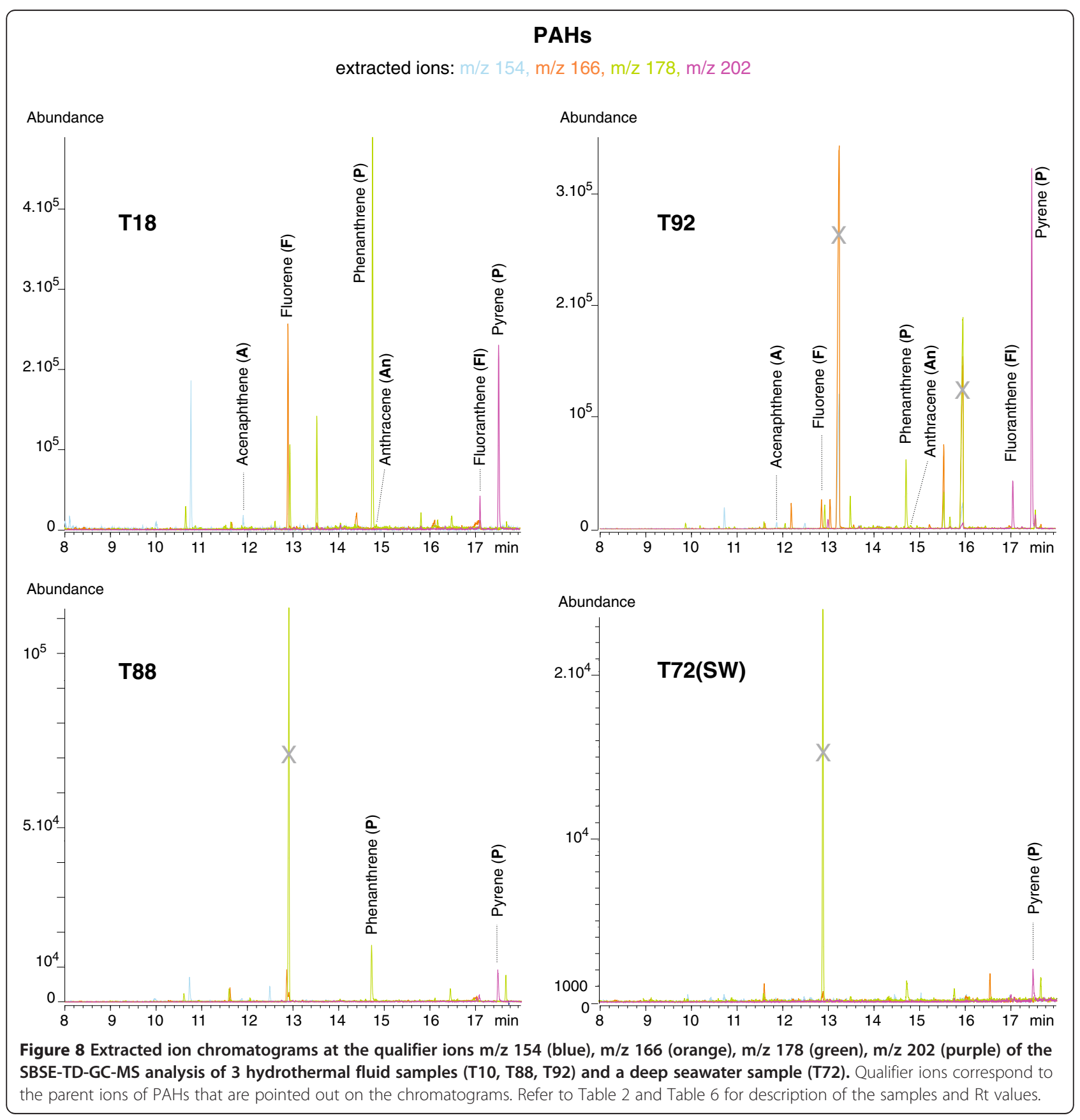


volatility of longer chain fatty acids when underivatized. We observed a slight offset between the Rt of the standards and those of the hydrothermal fluids. Carboxylic acids in the range of $C_{8: 0}$ to $C_{14: 0}$ eluted 0.02-0.09 min earlier in the hydrothermal fluids whereas the $C_{16: 0}-C_{18: 0}$ eluted 0.06-0.1 min later (Table 3). We believe that this off-set is due to concentration differences because the higher the concentration the larger were the peaks and the longer their tails. This resulted in a shift in Rt [13].

Linear carboxylic acids detected in the hydrothermal fluids were in the $\mathrm{C}_{9: 0}-\mathrm{C}_{18: 0}$ range and showed an even carbon number predominance. This may indicate a biogenic contribution as living organisms are preferentially made of even carbon numbered fatty acids in the $\mathrm{C}_{12: 0}-\mathrm{C}_{22: 0}$ range [46]. By contrast, Fischer Tropsch Type abiogenic reactions, that likely occur in hydrothermal systems, generate $C_{6: 0}-C_{22: 0} n$-fatty acids without carbon number selectivity, but result in a far larger number of shorter chain compounds $\left(\mathrm{C}_{6: 0}-\mathrm{C}_{10: 0}\right)$ [47,48]. Under hydrothermal conditions and at temperatures above $250^{\circ} \mathrm{C}$, cracking processes might also be responsible for the presence of short chain fatty acids in hydrothermal fluids from the Rainbow field [48]. The distribution of fatty acids in hydrothermal fluids may well be affected by dissolution, adsorption and complexation reactions that likely occur during hydrothermal circulation. It is therefore premature to draw conclusions at this stage based on the present preliminary observations.

\section{n-Alkanes}

We recorded a signal for each of the n-alkanes present in the standard solution. The highest response was obtained for $\mathrm{C}_{11}$ and $\mathrm{C}_{12} \mathrm{n}$-alkanes. The peak's areas corresponding to $C_{9}, C_{10}$ and $C_{13}$ were about $50 \%$ those of the $C_{11}$ and $\mathrm{C}_{12}$ n-alkanes. We observed a consistent decrease of the peak areas from $\mathrm{C}_{11}$ to $\mathrm{C}_{16}(100 \%$ to $3.5 \%)$. $\mathrm{C}_{15}-\mathrm{C}_{20}$ were easily detected, albeit exhibiting a much weaker signal ( $1.5 \%$ of $C_{11}$ peak area). n-Alkanes were clearly identified in the Total Ion Currents (TICs) of hydrothermal fluids by extracting ion $\mathrm{m} / \mathrm{z} 57$ (major ion) and 85 (confirmation

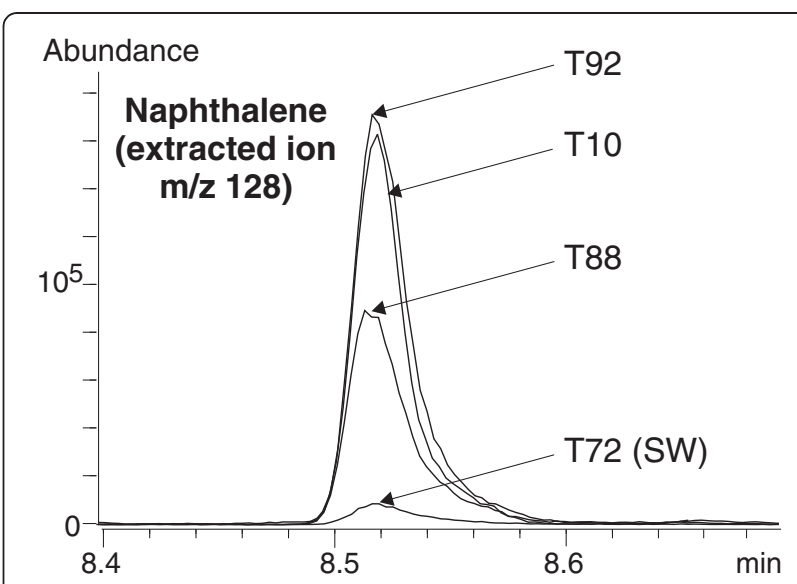

Figure 9 Zoom of extracted ion chromatograms at the qualifier ion $\mathrm{m} / \mathrm{z} 128$ (naphthalene) of the SBSE-TD-GC-MS analysis of 3 hydrothermal fluid samples (T10, T88, T92) and a deep seawater sample (T72). Arrows point out each sample signal. See Table 2 and Table 6 for description of the samples and Rt values.

ion). These ions are characteristic of $n$-alkanes and are formed via simple fragmentation mechanisms with bond cleavage. The whole series of n-alkanes except for eicosane could be detected in the hydrothermal fluid extracts (Figure 5). The Rt obtained for $\mathrm{C}_{9}-\mathrm{C}_{19} \mathrm{n}$-alkanes in hydrothermal fluids of the Rainbow site were almost identical (+ 0.01-0.06 s) to the synthetic standards ones (Table 4). $\mathrm{C}_{16}-\mathrm{C}_{19}$ responses were low and of the same order of magnitude as observed for the standard solution. The highest response was obtained for decane $\left(C_{10}\right)$ and was about $25 \%$ higher than for undecane $\left(C_{11}\right)$ and dodecane $\left(C_{12}\right)$. Also, the $C_{13}$ signal was far lower than that of $C_{14}$ contrary to what was observed in the standard solution. These variations in the distribution of carbon species may be indicators of specific chemical processes. The absence of $\mathrm{C}_{20}$ is probably due to a too high LOD. $\mathrm{C}_{12}$ and $\mathrm{C}_{15}$ were not reported previously because they were masked on the TICs by much more abundant co-eluting compounds. They could only be detected in this work by extracting ion $\mathrm{m} / \mathrm{z} 57$ and 85 .

Table 6 Retention times ( $\mathbf{R t}_{\text {stds }}$ ) of polyaromatic hydrocarbons (PAHs) obtained by SBSE-TD-GC-MS analyses of a standard mixture $(10 \mu \mathrm{g} / \mathrm{L})$

\begin{tabular}{|c|c|c|c|c|}
\hline Compounds & Molecular formula & $R t_{s t d s}(\min )$ & $R t_{\text {fluids }}(\min )$ & $m / z$ \\
\hline naphthalene $(\mathrm{N})$ & $\mathrm{C} 10 \mathrm{H} 8$ & 8.47 & 8.52 & 128 \\
\hline acenaphthene (A) & $\mathrm{C} 12 \mathrm{H} 10$ & 11.86 & 11.87 & 154 \\
\hline fluorene (F) & $\mathrm{C} 13 \mathrm{H} 10$ & 12.85 & 12.86 & 166 \\
\hline phenanthrene $(P)$ & $\mathrm{C} 14 \mathrm{H} 10$ & 14.70 & 14.71 & 178 \\
\hline anthracene (An) & $\mathrm{C} 14 \mathrm{H} 10$ & 14.79 & 14.81 & 178 \\
\hline fluoranthene (Fl) & $\mathrm{C} 16 \mathrm{H} 10$ & 17.04 & 17.06 & 202 \\
\hline pyrene $(P)$ & $\mathrm{C} 16 \mathrm{H} 10$ & 17.46 & 17.47 & 202 \\
\hline
\end{tabular}

Detection of the compounds was achieved using the molecular ion for each compound (last column). The NIST08 library was used for identification. Retention times ( $\mathrm{Rt}_{\text {fluids }}$ ) obtained in hydrothermal fluid samples of this study are given for direct comparison. 


\section{Monoaromatic hydrocarbons}

In our standard solution, monoaromatic hydrocarbons were much easier targeted in the SIM mode, using $\mathrm{m} / \mathrm{z}$ 91, 103.9, 104.9, 120 and 133.9, than in the full scan mode because of co-elution. Co-elution occurred because of the relatively high initial temperature $\left(40^{\circ} \mathrm{C}\right)$ of the $\mathrm{GC}$ oven, which could not be lowered. The tropylium ion $(\mathrm{m} / \mathrm{z} 91)$ is characteristic of BTEX but does not enable identification. The use of other confirmation ions and the NIST08 reference spectra were necessary for discrimination between isomers. All monoaromatic hydrocarbons were successfully identified in the standard mixture. Only toluene, styrene, p-, m-, o-xylene and ethylbenzene were detected in the hydrothermal fluids (Figure 6, Figure 7). The Rt obtained for the standard analysis and for hydrothermal fluids correlated very well (Table 5). The toluene response was highly variable in the hydrothermal fluids (Figure 7). This was also the case for the standard solutions and is commonly observed in SBSE-TD-GC-MS because of the high volatility of toluene (J. Guyomarch, personal communication). We do not exclude the occurrence of other BTEX but probably at concentrations below current LOD. Therefore the Rt for all compounds of the standard solution were reported in Table 5.

\section{Polyaromatic hydrocarbons (PAHs)}

PAHs were clearly evident on both full scan and SIM chromatograms of the standard solution. The resolution was extremely good as was the peak shape (Figure 8). The signal obtained for acenaphthene and fluorene was twice as low, whereas the response for other PAHs relative to napthlalene was $65-70 \%$. Detection of the whole series of PAHs in hydrothermal fluid samples was possible and achieved by extracting the parent ions (Table 6). Extracted ion chromatograms for PAHs are presented in Figure 8. Naphthalene showed the highest response and is thus presented separately for scale reasons (Figure 9). The Rt values were almost identical in the standard solutions and the natural samples (Table 6). Phenanthrene and pyrene signals were more than one order of magnitude higher than their respective isomers, anthracene and fluoranthene, in hydrothermal fluids. Unlike their behaviour in the standard solution, they all exhibited a similar response. The reason why anthracene and fluoranthene seem to occur in very low amounts and whether it is significant in terms of geochemical processes will be worth investigating.

\section{Blank and control experiments}

Because contamination cannot be totally excluded when dealing with natural samples, we put considerable effort into identifying contaminants. Dry blank experiments were carried out routinely. The dry blank Twister ${ }^{\circledR}$ was not used for sample extraction but was stored together with the rest of the batch, ensuring the detection of any contamination that could have occurred during conditioning, storage or

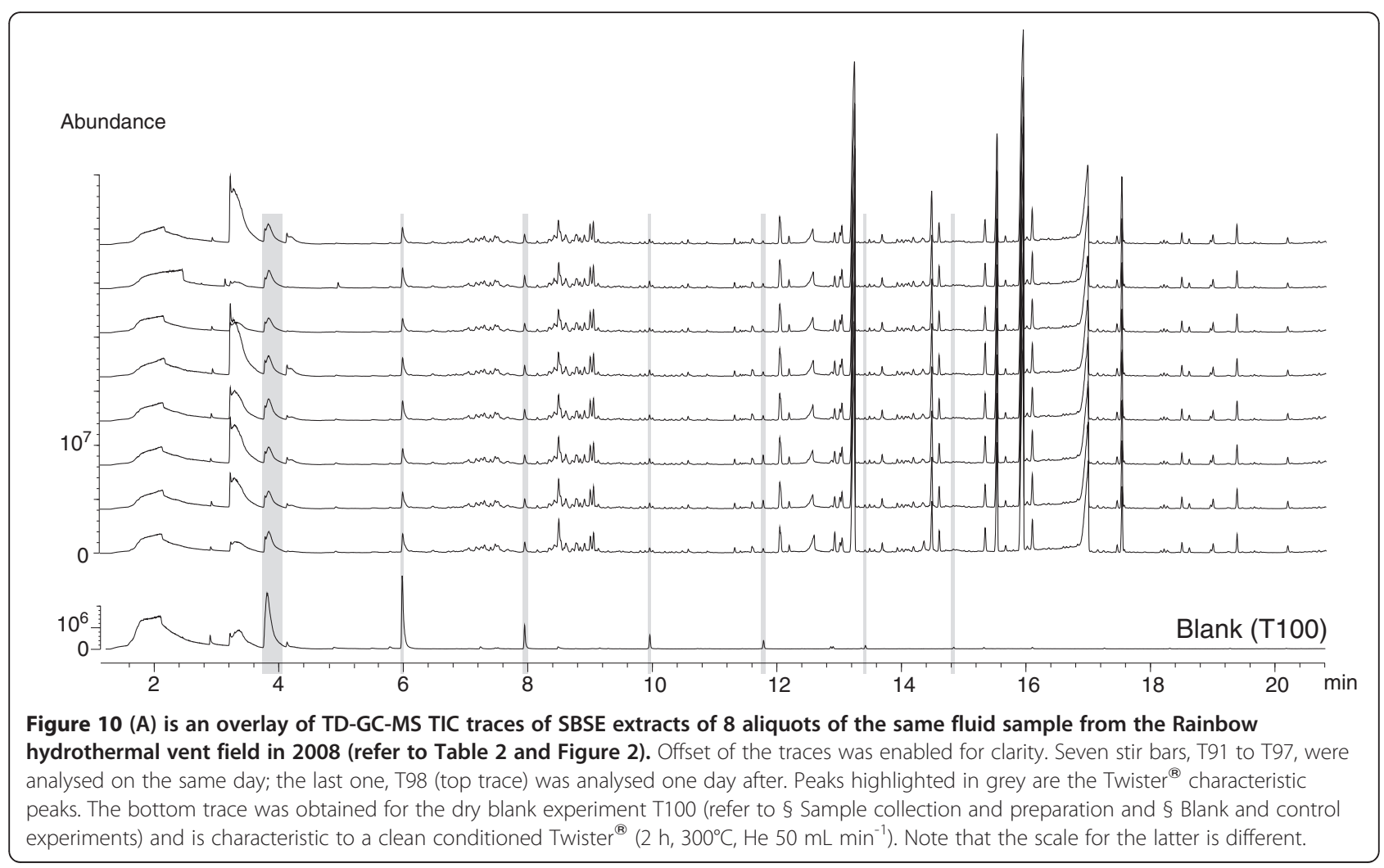


Table 7 Name, molecular formula and retention times (Rt) of the characteristic compounds that are leaked from the PDMS phase of the Twisters ${ }^{\circledR}$

\begin{tabular}{lcc}
\hline Compounds & Molecular formula & Rt (min) \\
\hline cyclotrisiloxane, hexamethyl- & $\mathrm{C} 6 \mathrm{H} 18 \mathrm{O} 3 \mathrm{Si3}$ & 3.80 \\
cyclotetrasiloxane, octamethyl- & $\mathrm{C} 8 \mathrm{H} 24 \mathrm{O} 4 \mathrm{Si} 4$ & 6.03 \\
cyclopentasiloxane, decamethyl- & $\mathrm{C} 10 \mathrm{H} 30 \mathrm{O} 5 \mathrm{Si} 5$ & 7.98 \\
cyclohexasiloxane, dodecamethyl- & $\mathrm{C} 12 \mathrm{H} 36 \mathrm{O} 6 \mathrm{Si} 6$ & 9.99 \\
cycloheptasiloxane, tetradecamethyl- & $\mathrm{C} 14 \mathrm{H} 42 \mathrm{O}$ Si7 & 11.82 \\
cyclononasiloxane, octadecamethyl- & $\mathrm{C} 18 \mathrm{H} 54 \mathrm{O} 9 \mathrm{Si9}$ & 14.88 \\
\hline
\end{tabular}

anything that was not related to sample preparation. TDGC-MS analyses of these dry blank Twisters ${ }^{\circledR}$ enabled us to establish that conditioning and storage were not sources of contamination in any of the samples used in this work. One representative example (T100) of the TIC of a dry blank can be seen in Figure 10. The TIC of a cleaned Twisters ${ }^{\circledR}$ is very characteristic, and consists of a series of siloxane peaks that have been highlighted in grey on all the TICs of this paper. The nature and Rt of these siloxanes are given in Table 7. These peaks always occur and cannot be removed by further conditioning.

Deep seawater was sampled each year in the neighbourhood of the Rainbow hydrothermal field, in a zone unaffected by hydrothermal discharge, to be used as a control experiment for identification of contaminants from both deep seawater and sampling equipment. Figure 11 shows the characteristic organic signature, obtained using the current method, of deep seawater in the vicinity of the Rainbow hydrothermal field. The major peaks appeared to be phthalates and chlorinated compounds originating from the pipette tips. Minor peaks were normally of a totally different nature - mostly N, P and $\mathrm{S}$ bearing compounds - than the one detected in hydrothermal fluids. Only a few hydrocarbons and fatty acids were observed, nevertheless the number and variety of molecules belonging to each group of compounds was far lower than in the hydrothermal fluids (Table 1).

Polymers may be altered and / or release compounds when exposed to the extreme $\mathrm{pH}$, high $\mathrm{H}_{2} \mathrm{~S}$ concentration and salinity of the hydrothermal fluids. PDMS stability and contamination issues with respect to $\mathrm{pH}, \mathrm{H}_{2} \mathrm{~S}$ concentration and variable salinity in experimental hydrothermal solutions have been studied elsewhere [13], however results are re-presented here. Twisters ${ }^{\circledR}$ were stirred in four solutions of various $\mathrm{pH}(3-12)$, salinity $\left(\left[\mathrm{Cl}^{-}\right]=5-835 \mathrm{mmol} \mathrm{kg}^{-1}\right)$ and $\mathrm{H}_{2} \mathrm{~S}$ concentration $\left(\left[\mathrm{H}_{2} \mathrm{~S}\right]=0-3.3 \mathrm{mmol} \mathrm{kg}^{-1}\right)$ that mimicked different hydrothermal conditions encountered at MOR. The TICs obtained are shown in Figure 12. The above listed parameters did not significantly affect the PDMS phase. Siloxane abundances generally increased when Twisters ${ }^{\circledR}$ were stirred in basic solutions [34] (C and D on Figure 12). Phthalates of various origins (PDMS phase, pipette tips, plastic ware) were detected when extracting acidic solutions (A and B on Figure 12). However, regardless of their source they are clearly contaminants. Other complex molecules appeared to a lesser degree and were described by the authors as clearly distinctly different from hydrothermally derived compounds (i.e., compounds that are thought to be inherent to hydrothermal fluids samples as opposed to contaminants). They

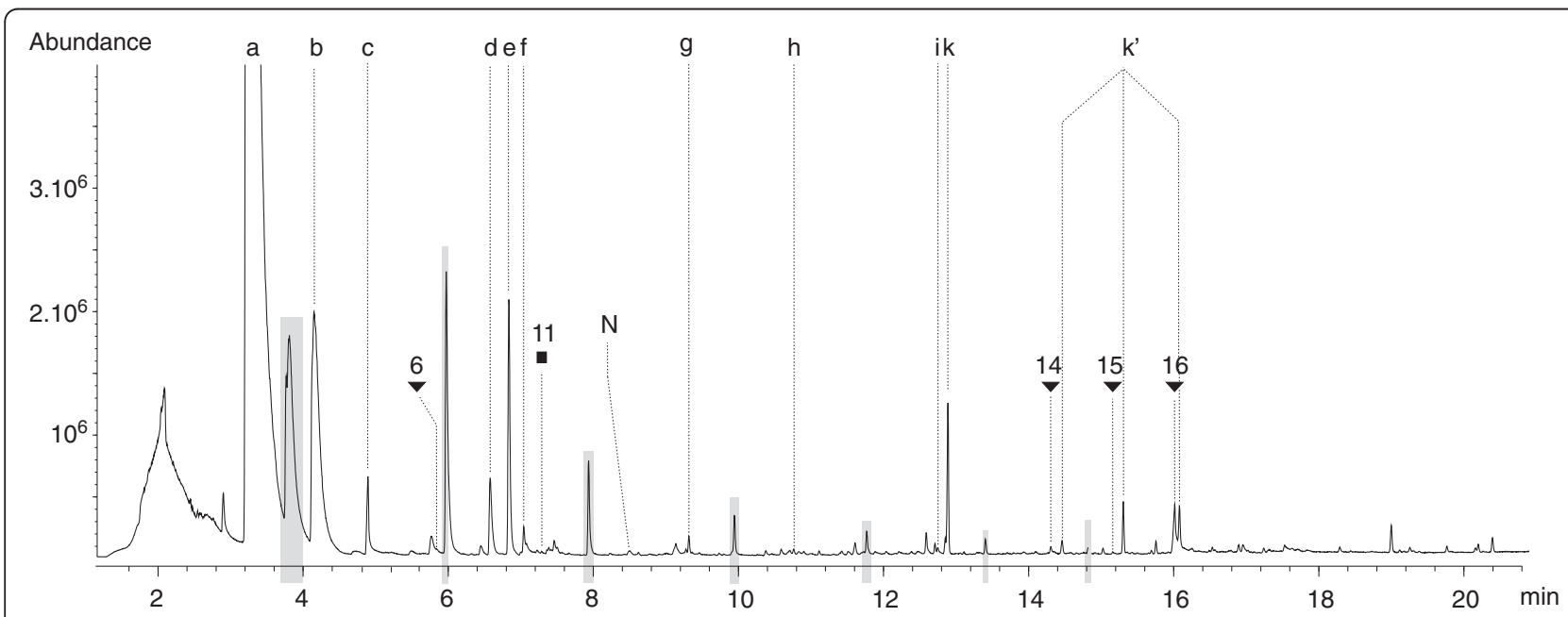

Figure 11 Representative TIC trace of the SBSE-TD-GC-MS analysis of $2000 \mathrm{~m}$ deep seawater in the neighbourhood of the Rainbow hydrothermal field. This particular sample was collected in 2007 at a depth of $2291 \mathrm{~m}$. Major contaminants are: (a) toluene; (b) benzene; chloro-; (c) oxime, methoxyphenyl; (d) benzene, 1,x-dichloro; (e) octane, 1-chloro; (f) siloxane; (g) decane, 1-chloro; (h) naphthalene, 2-chloro; (i) siloxane; (k) diethylphthalate; $\left(k^{\prime}\right)$ phthalates. Peaks highlighted in grey are the Twister ${ }^{\circledR}$ characteristic peaks. Numbers stand for the carbonated chain lenght of n-alkanes (full squares) and n-carboxylic acids (full triangles). $\mathrm{N}$ is short for Naphthalene. 


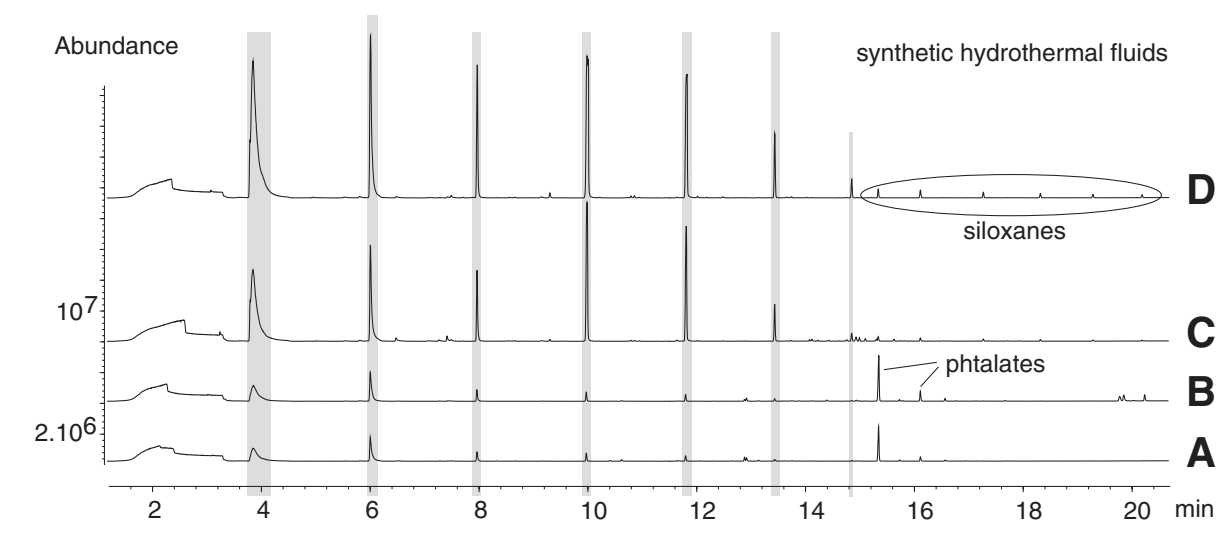

Figure 12 TIC traces obtained after TD-GC-MS analysis of Twisters ${ }^{\circledR}$ stirred in synthetic hydrothermal solutions. A: $\mathrm{pH}=5.46,[\mathrm{Cl}]=$ $835 \mathrm{mM},\left[\mathrm{H}_{2} \mathrm{~S}\right]=0.41 \mathrm{mM} . \mathbf{B}: \mathrm{pH}=3.13,[\mathrm{Cl}]=305 \mathrm{mM} . \mathbf{C}: \mathrm{pH}=11.35,[\mathrm{Cl}]=544 \mathrm{mM},\left[\mathrm{H}_{2} \mathrm{~S}\right]=0.13 \mathrm{mM} . \mathbf{D}: \mathrm{pH}=11.86,[\mathrm{Cl}]=5 \mathrm{mM},\left[\mathrm{H}_{2} \mathrm{~S}\right]=3.3 \mathrm{mM}$. TICs were overlaid and are presented here with an offset for clarity.

consist of common plasticizers or polymer industryrelated compounds.

\section{Repeatability}

In order to validate the repeatability of SBSE-TD-GCMS for the analyses of organic compounds in hydrothermal fluids, a replicate experiment was carried out. Nine Twisters ${ }^{\circledR}$ were conditioned together (T91 to T98 and T100). T91 to T98 were stirred separately in aliquots of the same hydrothermal fluid sample (MOM-D4-Ti3), while T100 was kept as a dry blank reference (Table 2 and Figure 2). Seven of the stir bars were analysed sequentially, alternating with empty runs, on the same day and the last one was analysed on the following day.
Toluene abundances differed among the samples (Figure 10). Strong abundance variations are commonly observed in TD-GC-MS (J. Guyomarch, personnal communication) Nevertheless, all TICs strictly superimposed (Figure 10), which shows an excellent qualitative repeatability of the entire method from sample preparation to analysis.

\section{Temporal sample stability}

T11 was analysed in 2005 just a few weeks after the end of the EXOMAR cruise during which samples were collected and extracted. A duplicate of the same sample extract (T10) was stored and analysed three years later. Figure 13 shows the TICs recorded after TD-GC-MS

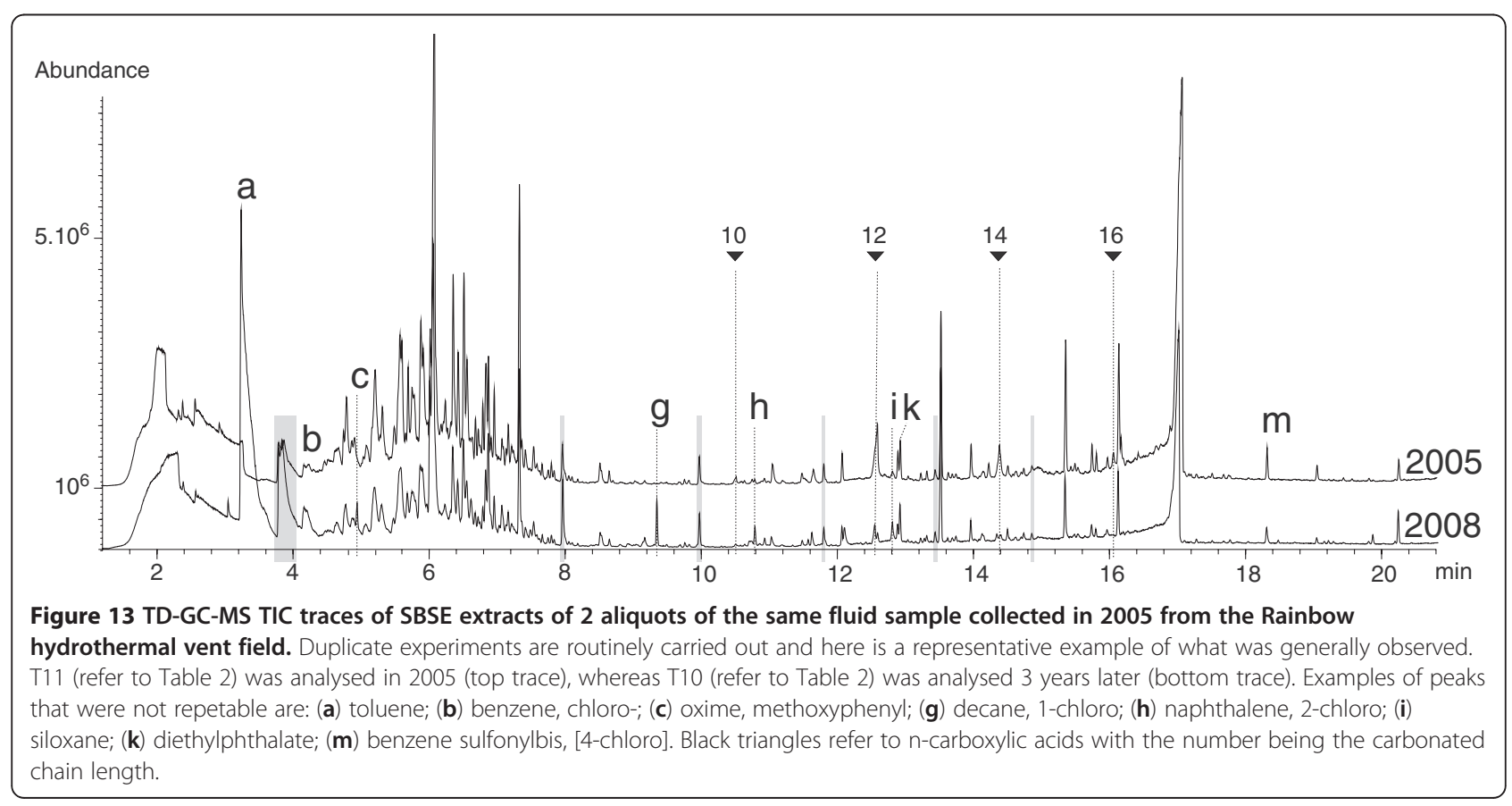


Table 8 List of major compounds proposed to be inherent of hydrothermal fluids and detected in in the Rainbow fluid samples

\begin{tabular}{|c|c|c|c|c|c|}
\hline \multicolumn{3}{|l|}{ namor } & \\
\hline Compounds & Molecular formula & $R t$ (min) & n-decanoic acid & $\mathrm{C} 10 \mathrm{H} 20 \mathrm{O} 2$ & $10.52^{*}$ \\
\hline toluene & $\mathrm{C} 7 \mathrm{H} 8$ & $3.26^{*}$ & tetradecane & $\mathrm{C} 14 \mathrm{H} 30$ & $10.79^{*}$ \\
\hline ethylbenzene & $\mathrm{C} 8 \mathrm{H} 10$ & $4.34^{*}$ & naphthalene, ?,?-dimethyl- & $\mathrm{C} 12 \mathrm{H} 12$ & $11.21+$ \\
\hline p-xylene / m-xylene & $\mathrm{C} 8 \mathrm{H} 10$ & $4.43^{*}$ & acenaphthene & $\mathrm{C} 12 \mathrm{H} 10$ & $11.87^{*}$ \\
\hline cyclohexane, 1,?,? -trimethyl- & $\mathrm{C} 9 \mathrm{H} 18$ & $4.48+$ & dodecanoic acid & $\mathrm{C} 12 \mathrm{H} 24 \mathrm{O} 2$ & $12.58^{*}$ \\
\hline cyclohexane, 1,?,? -trimethyl- & $\mathrm{C} 9 \mathrm{H} 18$ & $4.53 \dagger$ & hexadecane & $\mathrm{C} 16 \mathrm{H} 34$ & $12.81^{*}$ \\
\hline cyclohexane, 1-methyl, ?-ethyl- & $\mathrm{C} 9 \mathrm{H} 18$ & $4.65 \dagger$ & fluorene & $\mathrm{C} 13 \mathrm{H} 10$ & $12.86^{*}$ \\
\hline o-xylene & $\mathrm{C} 8 \mathrm{H} 10$ & $4.71^{*}$ & heptadecane & $\mathrm{C} 17 \mathrm{H} 36$ & $13.74^{*}$ \\
\hline styrene & $\mathrm{C} 8 \mathrm{H} 8$ & $4.71^{*}$ & tetradecanoic acid & $\mathrm{C} 14 \mathrm{H} 28 \mathrm{O} 2$ & $14.41^{*}$ \\
\hline nonane & $\mathrm{C} 9 \mathrm{H} 2 \mathrm{O}$ & $4.76^{*}$ & octadecane & $\mathrm{C} 18 \mathrm{H} 38$ & $14.62^{*}$ \\
\hline cyclohexane, 1-methyl, ?-ethyl- & $\mathrm{C} 9 \mathrm{H} 18$ & $4.88+$ & phenanthrene & $\mathrm{C} 14 \mathrm{H} 10$ & $14.71^{*}$ \\
\hline cyclohexane, -propyl & $\mathrm{C} 9 \mathrm{H} 18$ & $5.18+$ & anthracene & $\mathrm{C} 14 \mathrm{H} 10$ & $14.81^{*}$ \\
\hline branched alkane & $\mathrm{C} 10 \mathrm{H} 22$ & $5.22+$ & pentadecanoic acid & $\mathrm{C} 15 \mathrm{H} 30 \mathrm{O} 2$ & $15.23+$ \\
\hline cyclohexane, 1-ethyl, ?,?-dimethyl- & $\mathrm{C} 10 \mathrm{H} 20$ & $5.33+$ & nonadecane & $\mathrm{C} 19 \mathrm{H} 40$ & $15.47^{*}$ \\
\hline branched alkane & $\mathrm{C} 10 \mathrm{H} 22$ & $5.51+$ & n-hexadecanoic acid & $\mathrm{C} 16 \mathrm{H} 32 \mathrm{O} 2$ & $16.12^{*}$ \\
\hline branched alkane & $\mathrm{C} 10 \mathrm{H} 22$ & $5.59+$ & cyclic octaatomic sulfur & S8 & $17.10+$ \\
\hline branched alkane & $\mathrm{C} 10 \mathrm{H} 22$ & $5.70+$ & fluoranthene & $\mathrm{C} 16 \mathrm{H} 10$ & $17.06^{*}$ \\
\hline cyclohexane, 1-methyl, ?-propyl- & $\mathrm{C} 10 \mathrm{H} 2 \mathrm{O}$ & $5.89+$ & pyrene & $\mathrm{C} 16 \mathrm{H} 10$ & $17.47^{*}$ \\
\hline phenol & $\mathrm{C} 6 \mathrm{H} 6 \mathrm{O}$ & $5.96+$ & octadecanoic acid & $\mathrm{C} 18 \mathrm{H} 36 \mathrm{O} 2$ & $17.61^{*}$ \\
\hline decane & $\mathrm{C} 10 \mathrm{H} 22$ & $6.05^{*}$ & Rt is the retention time obt & nt analytica & * this \\
\hline cyclohexane, 1-methyl, ?-propyl- & $\mathrm{C} 10 \mathrm{H} 22$ & $6.18+$ & & & \\
\hline
\end{tabular}

$\mathrm{C} 13 \mathrm{H} 28$

$\mathrm{C} 13 \mathrm{H} 28$

$\mathrm{C} 11 \mathrm{H} 24$

$\mathrm{C} 10 \mathrm{H} 20$

$\mathrm{C} 11 \mathrm{H} 24$

branched alkane

branched cyclohexane

branched alkane

naphtalene, decahydro-, trans

branched alkane

branched alkane

branched cyclohexane

undecane

cyclohexane, 1-methylbutyl-

branched alkane

cyclohexane, pentyl-

cyclopentane, hexyl-

branched alkane

branched alkane

octanoic acid

naphtalene

nonanoic acid

tridecane

naphthalene, ?-methyl-
Table 8 List of major compounds proposed to be inherent of hydrothermal fluids and detected in in the Rainbow fluid samples (Continued)

analysis of T11 and T10 (Table 2). The peaks attributed to the $\mathrm{C}_{10: 0-16: 0}$ carboxylic acids appeared smaller on the TIC obtained after 3 years of storage. At the present time and without the use of internal standards, we consider that the differences are due to a combination of common factors that affect the signal: aging of the machine and especially the electron multiplier, routine replacement of liner, as well as small differences in the vacuum level after maintenance of the apparatus. Some differences, such as the presence / absence of a peak, were also evident. They mostly affected the nonhydrothermally derived compounds, and a few examples of this are indicated in Figure 13. A general trend, observed not only in the TIC examples presented here, was that siloxane and chlorinated compound peaks seem to produce a much larger signal after a long storage period. Unfortunately, experimental restrictions prevented us from including more than one dry blank per batch of Twister $^{\circledR}$ and one control experiment per cruise. Consequently, this interpretation will need to be tested in the future with the assistance of internal standards. Additional siloxanes commonly originate from other plastic ware such as septa. They were observed on TICs of empty runs which indicates an origin from the TD-GC-MS system itself (O-rings, septa...) Despite 
those few striking differences, TICs superimposed well and a detailed identification of each peak revealed the presence of the same hydrothermally derived organic compounds, i.e., n-alkanes, branched alkanes, cycloalkanes, aromatic hydrocarbons, PAHs and n-carboxylic acids in both samples [13]. Even though some variations in abundance may occur, no total loss of a compound or strong variations in terms of hydrothermally derived compounds were observed. All this infers that the recovered organic composition, using the current approach, is qualitatively preserved over a three-year storage period.

\section{Implication for the study of hydrothermal organic geochemistry}

A wide variety of organic compounds have been recovered and analysed by SBSE-TD-GC-MS in numerous hydrothermal fluid samples. n-Alkanes, cycloalkanes, branched alkanes, BTEX and PAHs, as well as ncarboxylic acids have been identified and reported by Konn et al. [13] (Table 8). These occurrences are supported by field [4-8,14], experimental ([49] and references therein) and theoretical observations [50]. Little is known of the overall geophysical and geochemical processes that control, on the one hand, the formation of organic compounds in hydrothermal systems and on the other hand, their distribution and dissolution in the fluid. First of all, mantle $\mathrm{CO}_{2}$ and living organisms are potential primary carbon sources to build up molecules. Secondly, several processes either abiogenic (catalytic reactions such as Fischer-Tropsch synthesis) $[11,12,16]$, thermogenic [44] or biogenic (e.g. methanogens archaea) may be involved in the organic synthesis in hydrothermal systems. The extent to which each carbon source and process may contribute to the formation of organic compounds is unknown. Finally, seawater is thought to reach a supercritical state ( $\mathrm{Tc}=$ $407^{\circ} \mathrm{C}, \mathrm{Pc}=298$ bar) in seafloor hydrothermal systems and chemical reactions that take place under such conditions are largely uncharacterised [51]. The distribution and dissolution of organic compounds in hydrothermal fluids may be affected by the inorganic geochemistry and phase separation. The inorganic geochemistry of the Rainbow fluids is well documented. Several papers have presented evidence for the presence of a single fluid source fuelling all vents; concentrations of elements and gases have been stable for decades (e.g. $[9,16])$. However, the possibility of a link between the organic and the inorganic geochemistry of seafloor hydrothermal fluids has not been investigated. It is currently unknown whether the organic composition (type of compounds present, concentrations) varies with time or geographical position of hydrothermal systems. SBSE-TD-GC-MS analyses of hydrothermal fluid samples will be essential in understanding the geochemical processes controlling the organic geochemistry of hydrothermal fluids, as well as to investigate the influence of time and location on hydrothermal fluids organic geochemistry.

We have demonstrated in the previous 4 sections that SBSE-TD-GC-MS is a method suitable for the qualitative analyses of a portion of the dissolved organic matter in small sample volumes of hydrothermal fluids. It is especially: (i) a method whose few contaminants can easily be distinguished, (ii) a repeatable method, and (iii) a

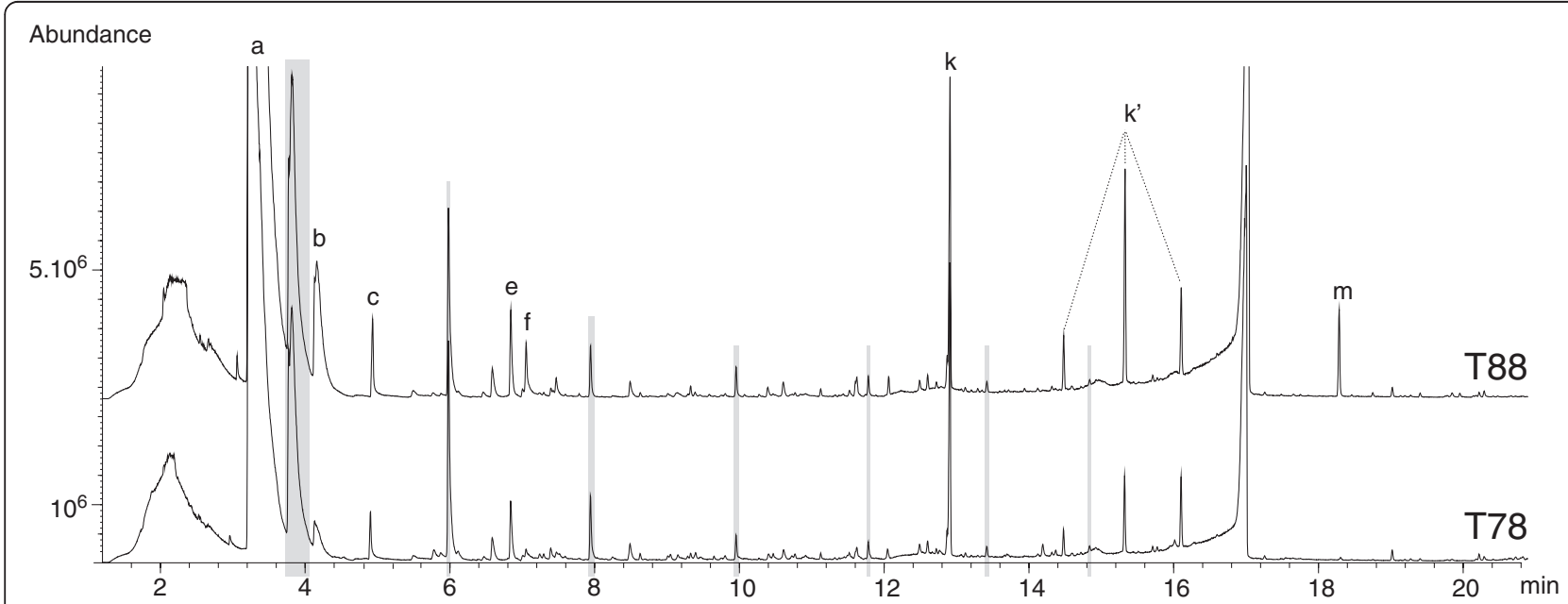

Figure 14 These two TD-GC-MS TIC traces are a representative choice of the results obtained after Twister ${ }^{\circledR}$ extraction of the fluids from the Rainbow hydrothermal vent field collected in 2007 in the south-west area B, T88 (refer to Table 2) (top) and in the north-east area C, T78 (refer to Table 2) (bottom). Examples of peaks that appeared in obvious different abundance are pointed out: (a) toluene; (b) benzene, chloro-; (c) oxime, methoxyphenyl; (e) octane, 1-chloro; (f) siloxane; (k) diethylphthalate; (k') phthalatephthalates; (m) benzene sulfonylbis, [4-chloro]. 


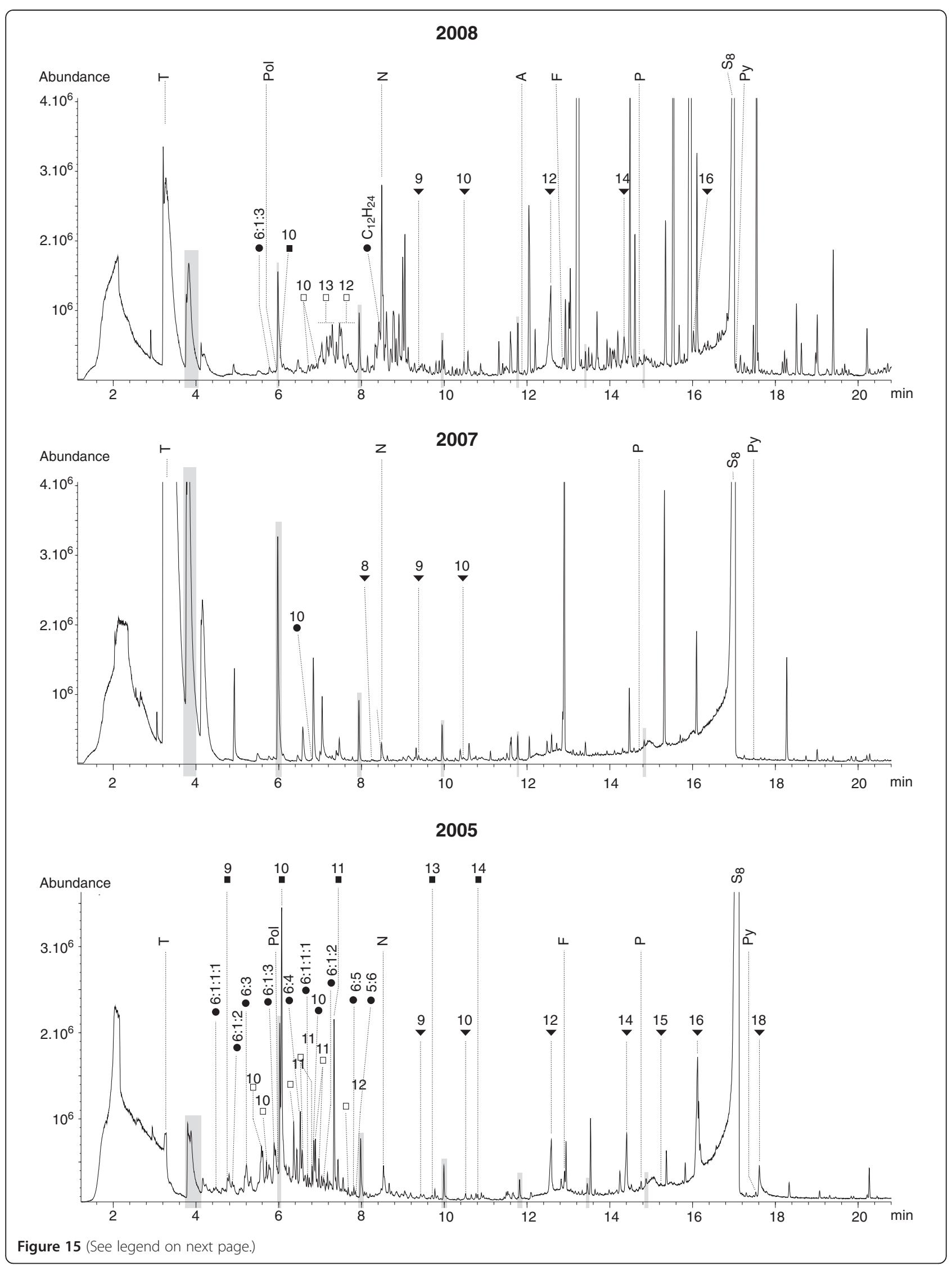


(See figure on previous page.)

Figure 15 These three TD-GC-MS TIC traces are a representative choice of the results obtained after Twister ${ }^{\circledR}$ extraction of the fluids from the Rainbow hydrothermal vent field in 2005 (bottom), 2007 (center) and 2008 (top). Numbers stand for the carbonated chain length of $\mathrm{n}$-alkanes (full squares), branched alkanes (empty squares) and n-carboxylic acids (full triangles). Cycloalkanes (full circles) are distinguished by the number of carbon in the cycle (first figure) and the number of carbon of the side chain(s) (following figure(s)). T, Pol, N, A, P and Py, and are short for toluene, phenol, naphthalene, acenaphthene, phenanthrene, and pyrene. Cyclooctaatomic sulfur $\left(S_{8}\right)$ was pointed because the peak was major. Highlighted in grey is the characteristic Twister's signature. Monoaromatic hydrocarbons appeared too small and were not pointed on the TICs for sake of clarity.

method that enables storage of samples for at least three years. In addition, we obtained positive preliminary results from a successful comparative study dedicated to the Rainbow ultramafic-hosted hydrothermal field. Comparison of samples collected in different chimneys (T88 and T78; see Table 2, Figure 2) suggests a homogeneous organic geochemistry over the entire Rainbow field (Figure 14). In contrast, a time series study (sampling in 2005, 2007 and 2008) revealed strong variations over the years of the organic contents of the fluids from the Rainbow field (Figure 15, Table 8). These significant variations are real and meaningful. They are definitely not artifacts caused by the method of analysis or sample preparation technique used. They also are unlikely to be due to weekly or daily events such as tides because samples were collected at random times over a three to sixweek period of time during cruises. These data show that this technology has a great potential for comparing the organic compositions of fluids originating from the same hydrothermal field (identical matrix). Therefore SBSE-TD-GC-MS analyses will be very useful in assessing intrafield variations (i.e., differences from one black smoker to another), in making interfield comparison, as well as carrying out time series studies.

Hydrothermal fluids most likely contain other organic molecules that cannot be recovered and / or detected using the current method. Firstly because of a molecule polarity issue [28], and secondly because some compounds may be undissolved (e.g., bound to salts or coordinated by metal ions). Therefore "organic composition" and "organic content" should only refer to the range of organic compounds that could be recovered and identified using our method, and likely represents a portion, consisting mainly of nonpolar compounds, of the total organic content of the hydrothermal fluids. All conclusions should only apply to that portion and in any case they should not be extrapolated to the total organic matter present in the hydrothermal fluids. However, SBSE has the versatility and the efficiency to greatly contribute to the understanding of organic geochemistry and geochemical processes of hydrothermal systems.

\section{Conclusions}

This study has shown that SBSE-TD-GC-MS can be applied successfully for qualitative detection of a wide range of dissolved organic compounds in seafloor hydrothermal fluids. The organic content recovered using the current method likely represents a portion, with a predominance of nonpolar compounds, of the total dissolved organic matter present in the hydrothermal fluids. Precise identification and determination of the Rt of n-carboxylic acids, n-alkanes, BTEX and PAHs was achieved by comparison to synthetic standard mixtures. The analyses of eight replicates demonstrated the extremely good repeatability of the SBSE-TD-GC-MS method. Analyses of replicates of Twisters ${ }^{\circledR}$ stored for three years appeared to reproduce earlier results reliably, showing that SBSE is an excellent way of preserving the recovered organic signature of a sample. It is furthermore very suitable as a sample preparation technique to be used on board a research vessel and potentially in-situ.

The versatile and robust SBSE-TD-GC-MS technology allows comparative-qualitative studies provided the sample matrices are identical. In a case study, the recovered organic content of the fluids from the Rainbow Ultramafic-hosted hydrothermal system were compared in respect to the location and year of sampling. The same compounds were identified in fluids regardless of the sampling location. These preliminary results suggest a relative homogeneity in the dissolved organic content of fluids over the entire Rainbow field. Unlike, strong differences were observed among the years over the 2005-2008 time period.

The organic geochemistry of hydrothermal vents is highly relevant to issues of the origin of life on the early Earth and of the production of abiogenic hydrocarbons in these systems. In addition, organic compounds constitute carbon sources for microbial communities. The use of the SBSE-TD-GC-MS method for the study of hydrothermal organic geochemistry will contribute extensively to the understanding of the geochemical processes controlling the formation and distribution of the compounds as well as the interactions with rocks, minerals, metals and organisms.

\section{Competing interests}

The authors declare that they have no competing interests.

\section{Authors' contributions}

CK carried out the SBSE analyses, interpreted the results and drafted the manuscript. JLC and JPD carried out sample collection, sample preparation for organic geochemistry and inorganic geochemistry analyses $\left(\mathrm{pH}, \mathrm{H}_{2} \mathrm{~S}, \mathrm{Cl}^{-}\right.$, 
etc... .). NGH participated in the design of the study and helped to draft the manuscript. All authors read and approved the final manuscript.

\section{Acknowledgements}

We thank Anne Godfroy, Françoise Gaill and Jerôme Dyment chief scientists of the EXOMAR (2005), MOMARDREAM-Naut (2007) and MOMAR08-Leg2 (2008) cruises, respectively, who allowed us to participate to their cruise and to collect and use hydrothermal fluid samples for this study. We are also very thankful to IFREMER, the ROV Victor 6000 team, the Nautile team, the RN Pourquoi pas? crew and the R/N I'Atalante crew for organisation and precious help. We are very grateful to Julien Guyomarch and all anonymzous reviewers for their constructive comments. This work has been carried out partly within the MoMARnet (Monitoring deep seafloor hydrothermal environments on the Mid-Atlantic Ridge: A Marie Curie Research Training network) framework, that provided the research funding.

Received: 27 October 2011 Accepted: 2 August 2012

Published: 7 November 2012

\section{References}

1. Engel MH, Macko SA: Organic Geochemistry: Principles and Applications. New York: Plenum Press; 1993.

2. Macleod G, McKeown C, Hall AJ, Russell MJ: Hydrothermal and oceanic pH conditions of possible relevance to the origin of life. Origins Life Evol. B. 1994, 24(1):19-41.

3. Russell MJ, Hall AJ, Boyce AJ, Fallick AE: $100^{\text {th }}$ Anniversary Special Paper: On Hydrothermal Convection Systems and the Emergence of Life. Econ Geol 2005, 100(3):419-438.

4. Simoneit BRT, Lein AY, Peresypkin VI, Osipov GA: Composition and origin of hydrothermal petroleum and associated lipids in the sulfide deposits of the Rainbow field (Mid-Atlantic Ridge at $36^{\circ} \mathrm{N}$ ). Geochim. Cosmochim. Acta 2004, 68(10):2275.

5. Delacour A, Früh-Green GL, Bernasconi SM, Schaeffer P, Kelley DS: Carbon geochemistry of serpentinites in the Lost City Hydrothermal System (30N, MAR). Geochim Cosmochim Acta 2008, 72(15):3681-3702.

6. Bradley AS, Fredricks H, Hinrichs K-U, Summons RE: Structural diversity of diether lipids in carbonate chimneys at the Lost City Hydrothermal Field. Org Geochem 2009, 40(12):1169-1178.

7. Bradley AS, Hayes JM, Summons RE: Extraordinary ${ }^{13} \mathrm{C}$ enrichment of diether lipids at the Lost City Hydrothermal Field indicates a carbonlimited ecosystem. Geochim Cosmochim Acta 2009, 73:102-118.

8. Peng X, Li J, Zhou H, Wu Z, Li J, Chen S, Yao H: Characteristics and source of inorganic and organic compounds in the sediments from two hydrothermal fields of the Central Indian and Mid-Atlantic Ridges. J. Asian Earth Sci. 2011, 41:355-368.

9. Charlou $\mathrm{JL}$, et al: High production and fluxes of $\mathrm{H} 2$ and $\mathrm{CH}_{4}$ and evidence of abiotic hydrocarbon synthesis by serpentinization in ultramafic-hosted hydrothermal systems on the Mid-Atlantic Ridge. In Diversity of Hydrothermal Systems on Slow-spreading Ocean Ridges. Edited by Rona P, Devey C, Dyment J, Murton B. Washington DC: Geophysical Monograph Series; 2010:265-296.

10. Kelley DS, Baross JA, Delaney JR: Volcanoes, Fluids, and Life at Mid-Ocean Ridge Spreading Centers. Annu. Rev. Earth PI. Sc. 2002, 30(1):385-491.

11. Proskurowski G, Lilley MD, Seewald JS, Fruh-Green GL, Olson EJ, Lupton JE, Sylva SP, Kelley DS: Abiogenic Hydrocarbon Production at Lost City Hydrothermal Field. Science 2008, 319(5863):604-607.

12. Holm NG, Charlou JL: Initial indications of abiotic formation of hydrocarbons in the Rainbow ultramafic hydrothermal system. Mid-Atlantic Ridge. Earth Planet. Sc. Let. 2001, 191(1-2):1-8.

13. Konn C, Charlou JL, Donval JP, Holm NG, Dehairs F, Bouillon S: Hydrocarbons and oxidized organic compounds in hydrothermal fluids from Rainbow and Lost City ultramafic-hosted vents. Chem Geol 2009, 258(3-4):299-314.

14. Lang SQ, Butterfield DA, Schulte M, Kelley DS, Lilley MD: Elevated concentrations of formate, acetate and dissolved organic carbon found at the Lost City hydrothermal field. Geochim Cosmochim Acta 2010, 74(3):941-952.

15. Butterfield DA, Massoth GJ, McDuff RE, Lupton JE, Lilley MD: Geochemistry of Hydrothermal Fluids From Axial Seamount Hydrothermal Emissions Study Vent Field. Juan de Fuca Ridge: Subseafloor Boiling and
Subsequent Fluid-Rock Interaction. J Geophys Res-Solid 1990, 95(B8):12895-12921.

16. Charlou JL, Donval JP, Fouquet $Y$, Jean-Baptiste P, Holm N: Geochemistry of high $\mathrm{H}_{2}$ and $\mathrm{CH}_{4}$ vent fluids issuing from ultramafic rocks at the Rainbow hydrothermal field ( $\left.36^{\circ} 14^{\prime} \mathrm{N}, \mathrm{MAR}\right)$. Chem Geol 2002, 191(4):345-359.

17. Foustoukos DI, Seyfried WE Jr: Fluid Phase Separation Processes in Submarine Hydrothermal Systems. Rev Mineral Geochem 2007, 65(1):213-239.

18. Von Damm KL, Buttermore LG, Oosting SE, Bray AM, Fornari DJ, Lilley MD, Shanks lii WC: Direct observation of the evolution of a seafloor 'black smoker' from vapor to brine. Earth Planet. Sc. Let. 1997, 149(1-4):101-111.

19. Hennion M-C: Solid-phase extraction: method development, sorbents, and coupling with liquid chromatography. J Chromatogr A 1999, 856(1-2):3-54.

20. Arthur CL, Pawliszyn J: Solid phase microextraction with thermal desorption using fused silica optical fibers. Anal Chem 1990, 62(19):2145-2148.

21. Segal A, Górecki T, Mussche P, Lips J, Pawliszyn J: Development of membrane extraction with a sorbent interface-micro gas chromatography system for field analysis. J Chromatogr A 2000, 873(1):13-27.

22. Handley AJ: Extraction Methods in Organic Analysis. Sheffield: Academic Press Ltd.; 1999

23. Smith RM: Supercritical fluids in separation science - the dreams, the reality and the future. J Chromatogr A 1999, 856(1-2):83-115.

24. Carabias-Martínez R, Rodríguez-Gonzalo E, Revilla-Ruiz P, Hernández-Méndez $\mathrm{J}$ : Pressurized liquid extraction in the analysis of food and biological samples. J Chromatogr A 2005, 1089(1-2):1-17.

25. Shu YY, Lao RC, Chiu CH, Turle R: Analysis of polycyclic aromatic hydrocarbons in sediment reference materials by microwave-assisted extraction. Chemosphere 2000, 41(11):1709-1716.

26. Grosjean E, Logan GA: Incorporation of organic contaminants into geochemical samples and an assessment of potential sources: Examples from Geoscience Australia marine survey S282. Org Geochem 2007, 38(6):853.

27. David F, Sandra P: Stir bar sorptive extraction for trace analysis. J Chromatogr A 2007, 1152(1-2):54-69.

28. Baltussen E, Sandra P, David F, Cramers C: Stir bar sorptive extraction (SBSE), a novel extraction technique for aqueous samples: Theory and principles. J. Microcolumn Sep. 1999, 11(10):737-747.

29. Sandra P, Baltussen E, David F, Hoffmann A: A Novel Extraction Technique for Aqueous Samples: Stir Bar Sorptive Extraction. Gerstel Application Notes 2000, 1:2000

30. Ochiai N, Nakamura S: Application of Stir Bar Sorptive Extraction (SBSE) Coupled to Thermal Desorbtion GC-MS for Determination of Ultra-Trace Level Compounds of Aqueous Samples. Gerstel Application Note 2005, 5:2005.

31. Roy G, Vuillemin R, Guyomarch J: On-site determination of polynuclear aromatic hydrocarbons in seawater by stir bar sorptive extraction (SBSE) and thermal desorption GC-MS. Talanta 2005, 66(3):540-546.

32. Pérez-Carrera E, León VML, Parra AG, González-Mazo E: Simultaneous determination of pesticides, polycyclic aromatic hydrocarbons and polychlorinated biphenyls in seawater and interstitial marine water samples, using stir bar sorptive extraction-thermal desorption-gas chromatography-mass spectrometry. J Chromatogr A 2007, 1170(1-2):82-90.

33. León VM, Llorca-Pórcel J, Álvarez B, Cobollo MA, Muñoz S, Valor I: Analysis of 35 priority semivolatile compounds in water by stir bar sorptive extraction-thermal desorption-gas chromatography-mass spectrometry: Part II: Method validation. Anal Chim Acta 2006, 558(1-2):261-266.

34. Pfannkoch E, Whitecavage J, Hoffmann A: Stir Bar Sorptive Extraction: Enhancing Selectivity of the PDMS Phase. Gerstel Application Note 2001, 2:2001.

35. Bicchi C, Cordero C, Rubiolo P, Sandra P: Impact of water/PDMS phase ratio, volume of PDMS, and sampling time on Stir Bar Sorptive Extraction (SBSE) recovery of some pesticides with different $\mathrm{K}_{\mathrm{o} / \mathrm{w}}$. J Sep Sci 2003, 26:1650-1656.

36. MacNamara K, Leardi R, McGuigan F: Comprehensive investigation and optimisation of the main experimental variables in stir-bar sorptive extraction (SBSE)-thermal desorption-capillary gas chromatography (TD-CGC). Anal Chim Acta 2009, 636(2):190-197.

37. Pfannkoch E, Whitecavage J, Kinton V: Stir Bar Sorptive Extraction: Recovery of Organic Acids and Amines. Gerstel Application Note 2003, 5:2003. 
38. Sanderson $\mathrm{H}$, Thomsen M: Comparative analysis of pharmaceuticals versus industrial chemicals acute aquatic toxicity classification according to the United Nations classification system for chemicals. Assessment of the (Q)SAR predictability of pharmaceuticals acute aquatic toxicity and their predominant acute toxic mode-of-action. Toxicol Lett 2009, 187(2):84-93.

39. Fouquet Y, Charlou JL, Ondreas H, Knoery J, Donval JP, Douville E: Discovery and first submersible investigations on the Rainbow hydrothermal field on the MAR $\left(36^{\circ} 14^{\prime} \mathrm{N}\right)$. EOS Trans-Am Geophys Union 1997, 78:832.

40. Charlou JL, Fouquet Y, Bougault H, Donval JP, Etoubleau J, Jean-Baptiste P, Dapoigny A, Appriou P, Rona PA: Intense $\mathrm{CH}_{4}$ plumes generated by serpentinization of ultramafic rocks at the intersection of the $15^{\circ} 20^{\prime} \mathrm{N}$ fracture zone and the Mid-Atlantic Ridge. Geochim Cosmochim Acta 1998, 62(13):2323-2333.

41. Douville E, Charlou JL, Oelkers EH, Bienvenu P, Jove Colon CF, Donval JP, Fouquet Y, Prieur D, Appriou P: The rainbow vent fluids (36 Deg14' $\mathrm{N}$, $M A R)$ : the influence of ultramafic rocks and phase separation on trace metal content in Mid-Atlantic Ridge hydrothermal fluids. Chem Geol 2002, 184(1-2):37

42. Dyment J, et al: Detailed investigation of hydrothermal site Rainbow, Mid-Atlantic Ridge, $36^{\circ} 13^{\prime} \mathrm{N}$ : Cruise MoMARDream. InterRidge News 2009, 18:22-24.

43. Gaill F, et al: Cruise MoMARDREAM-Naut and other MoMAR Experiments at Rainbow and Lucky Strike in Summer 2007. InterRidge News 2007, 16:15-16.

44. Konn C, Testemale D, Querellou J, Holm NG, Charlou JL: New insight into the contributions of thermogenic processes and biogenic sources to the generation of organic compounds in hydrothermal fluids. Geobiology 2011, 9:79-93.

45. McLafferty FW: Mass Spectrometric Analysis. Molecular Rearrangements. Anal Chem 1959, 31:82-87.

46. Rezanka T, Sigler K: Odd-numbered very-long-chain fatty acids from the microbial, animal and plant kingdoms. Prog Lipid Res 2009, 48:206-238.

47. McCollom TM, Simoneit BR: Abiotic formation of hydrocarbons and oxygenated compounds during thermal decomposition of iron oxalate. Origins Life Evol B 1999, 29:167-186.

48. Rushdi Al, Simoneit BRT: Lipid Formation by Aqueous Fischer-TropschType Synthesis over a Temperature Range of 100 to $400^{\circ} \mathrm{C}$. Origins Life Evol B 2001, 31:103-118.

49. McCollom TM, Seewald JS: Abiotic Synthesis of Organic Compounds in Deep-Sea Hydrothermal Environments. Chem Rev 2007, 107(2):382-401.

50. Shock EL: Chapter 5 Chemical environments of submarine hydrothermal systems. Origins Life Evol B 1992, 22(1):67-107.

51. Peterson AA, Vogel F, Lachance RP, Froling M, Antal MJ Jr, Tester JW: Thermochemical biofuel production in hydrothermal media: A review of sub- and supercritical water technologies. Energy Environ Sci 2008, 1(1):32-65.

doi:10.1186/1467-4866-13-8

Cite this article as: Konn et al: Characterisation of dissolved organic compounds in hydrothermal fluids by stir bar sorptive extraction - gas chomatography - mass spectrometry. Case study: the Rainbow field $\left(36^{\circ}\right.$ N, Mid-Atlantic Ridge). Geochemical Transactions 2012 13:8.

\section{Submit your next manuscript to BioMed Central and take full advantage of:}

- Convenient online submission

- Thorough peer review

- No space constraints or color figure charges

- Immediate publication on acceptance

- Inclusion in PubMed, CAS, Scopus and Google Scholar

- Research which is freely available for redistribution 